\title{
Layered Ternary and Quaternary Transition Metal Chalcogenide Based Catalysts for Water Splitting
}

\author{
Anand P. Tiwari ${ }^{1,+}$, Travis G. Novak ${ }^{1,+}$, Xiuming Bu ${ }^{2}$, Johnny C. Ho ${ }^{2, *}$ and Seokwoo Jeon ${ }^{1, *(D)}$ \\ 1 Department of Materials Science and Engineering, KAIST Institute for the Nanocentury, Advanced Battery \\ Center, KAIST, Daejeon 305-701, Korea; anand@kaist.ac.kr (A.P.T.); travisnovak@kaist.ac.kr (T.G.N.) \\ 2 Department of Materials Science and Engineering, City University of Hong Kong, 83 Tat Chee Avenue, \\ Kowloon, Hong Kong; xiumingbu2-c@my.cityu.edu.hk \\ * Correspondence: johnnyho@cityu.edu.hk (J.C.H.); jeon39@kaist.ac.kr (S.J.); Tel.: +82-42-350-3342 (S.J.) \\ + These authors contributed equally.
}

Received: 30 October 2018; Accepted: 13 November 2018; Published: 16 November 2018

check for updates

\begin{abstract}
Water splitting plays an important role in the electrochemical and photoelectrochemical conversion of energy devices. Electrochemical water splitting by the hydrogen evolution reaction (HER) is a straightforward route to producing hydrogen $\left(\mathrm{H}_{2}\right)$, which requires an efficient electrocatalyst to minimize energy consumption. Recent advances have created a rapid rise in new electrocatalysts, particularly those based on non-precious metals. In this review, we present a comprehensive overview of the recent developments of ternary and quaternary 6d-group transition metal chalcogenides (TMCs) based electrocatalysts for water splitting, especially for HER. Detailed discussion is organized from binary to quaternary TMCs including, surface engineering, heterostructures, chalcogen substitutions and hierarchically structural design in TMCs. Moreover, emphasis is placed on future research scope and important challenges facing these electrocatalysts for further development in their performance towards water splitting.
\end{abstract}

Keywords: hydrogen; electrocatalysts; transition metal; layered material; heterostructure; hierarchical; surface engineering

\section{Introduction}

In recent years, there has been increasing attention on renewable and environmentally friendly energy devices and energy sources as alternatives to fossil fuels [1,2]. In materials science research, two-dimensional (2D) layered materials such as graphene, transition metal chalcogenides (TMCs), MXenes and phosphorene have been heavily researched for many of these energy applications, including solar cells, batteries, light-emitting diodes, thermoelectric generators and so forth [3-8]. These layered 2D materials have also been studied as efficient catalysts for the production of hydrogen, which has been proposed as the ideal energy carrier by virtue of its highest gravimetric energy density with zero emission of carbon dioxide $[9,10]$.

Hydrogen is not available in free form but mainly exists in compounds such as hydrocarbons and water. At present, hydrogen is mainly produced from natural gas via steam reforming of hydrocarbons, which produces a large amount of greenhouse-gas emissions, making it neither renewable nor carbon-neutral [11]. Therefore, current demand for hydrogen production is how to find a sustainable, economical and large scale route. In this respect, hydrogen production via electrolytic or photocatalytic water splitting is highly desired for renewable and environmentally-friendly hydrogen production [1,12]. The water splitting reaction is possible through two different cathodic half electrochemical reactions: the oxygen evolution reaction (OER) and hydrogen evolution reaction (HER). HER activity is pivotal to a range of energy conversion devices including artificial photosynthetic cells. 
HER activity proceeds through the reduction of protons accompanied be the subsequent evolution of gaseous hydrogen as follows:

In acidic electrolytes:

$$
2 \mathrm{H}_{(\mathrm{aq})}{ }^{+}+2 \mathrm{e} \rightarrow \mathrm{H}_{2(\mathrm{~g})}
$$

In alkaline electrolytes:

$$
2 \mathrm{H}_{2} \mathrm{O}+2 \mathrm{e}^{-} \rightarrow \mathrm{H}_{2(\mathrm{~g})}+2 \mathrm{OH}_{(\mathrm{aq})}{ }^{-}
$$

The standard reduction potential of the HER is defined versus a normal hydrogen electrode at $\mathrm{pH}=0$ as:

$$
E_{H^{+} / H_{2} \mathrm{O}}^{0}=0 \mathrm{~V}
$$

On top of the reduction potential, electrochemical processes have to surmount a certain activation energy barrier (known as overpotential) for water splitting activity to occur. Therefore, to promote the reaction rate and efficiency, HER activity demands the assistance of electrocatalysts to lower the overpotential $[13,14]$. In general, acidic electrolytes are more favorable because these units are more compact and could potentially run in reverse mode to produce electricity (i.e., in fuel cells) [15].

To date the most effective catalysts for the HER activity under acidic conditions are the platinum group metals (PGMs, including Pt, $\mathrm{Ru}, \mathrm{Rh}$, Ir and Pd). Among PGMs, $\mathrm{Pt}$ is the most popular choice, which has a near-zero overpotential and is frequently used to benchmark the activity of other HER electrocatalysts [16]. Nevertheless, the high price and shortage restrict the commercial application of PGMs for the HER electrocatalysts. Therefore, highly effective alternative HER electrocatalysts with good activity, high abundance and low cost [15] are key direction of research and two general strategies have been pursued. The first one is to use microstructured or nanostructured electrocatalysts with a large surface area. This is because electrocatalysis is a surface process, meaning that structures with a high surface area can significantly ease the demand on high catalyst loading [17]. The second strategy is to make alloy PGMs with other metals, which can increase their active sites, allowing for lower catalyst loading [18]. However, the non-homogeneous configuration of nanostructures in PGMs restricts the stability towards electrocatalytic activity.

Over the past decade, tremendous efforts have been actively made to replace the PGMs with many exciting advances $[19,20]$. In this regard, numerous earth-abundant compounds have been found to be competitive alternatives for PGMs, such as transition-metal dichalcogenides $\left(\mathrm{MoS}_{2}, \mathrm{WS}_{2}, \mathrm{TaS}_{2}\right.$, etc.), transition metal carbides ( $\mathrm{WC}, \mathrm{Mo}_{2} \mathrm{C}$, etc.) and transition metal phosphides (WP, MoP, etc.) for efficient electrocatalysis towards water splitting $[19,21]$. Among the non-noble metal catalysts, layered transition-metal chalcogenides (TMCs) $\left(\mathrm{MoS}_{2}, \mathrm{WS}_{2}\right)$ are promising because all of the catalytically active sites can be exposed due to atomically thin nature of 2D materials. Layered TMCs consist of alternating sheets of transition-metal atoms sandwiched between two chalcogen atoms [22]. The difference in oxidation degree (for metal +4 and for chalcogen -2 ) causes the formation of strong ionic bonds between the metal and the chalcogen atoms that preserve the structure of the nanosheets, whereas the existence of weak van der Waals bonds between the individual layers enables the exfoliation of bulk crystals down to single layers [23]. Moreover, a variety of compounds such as binary, ternary and quaternary TMCs with stoichiometric control of transition metals and chalcogens can provide us a rich platform to find the best electrocatalyst to replace the noble metals for water splitting. How the variations in chemistry of the different layered TMCs compounds lead to dramatic differences in their catalytic activity is one of main theme of the article.

Here we present a review on layered ternary and quaternary TMCs electrocatalysts with an emphasis on those made of $6 \mathrm{~d}$ transition metals (Mo and $\mathrm{W}$ ) and chalcogens ( $\mathrm{S}$ and Se). First, we start with a brief introduction to water splitting electrocatalysis especially in acidic medium by thermodynamics and possible reaction pathways. Consequently, it is followed by detailed discussions on different TMCs based on their compositions: binary (contains one type of $6 \mathrm{~d}$ transition metal and one type of chalcogen atoms), ternary (contains one type of $6 \mathrm{~d}$ transition metal and two type of chalcogen atoms or two type of $6 \mathrm{~d}$ transition metal and one type of chalcogen atoms) and 
quaternary (contains two type of transition metal and two type of chalcogen atoms) electrocatalysts for water splitting in sequential order. For each type of electrocatalyst, we emphasize the morphology and structure control and its relationship with the electrocatalytic activities toward $\mathrm{H}_{2}$ production. Specifically, we summarize major achievements and discuss prevailing trends for improvement in the electrocatalytic activities by variation in atomic constituents. We also give a detailed overview on the recent progress of hierarchical structure design of TMCs. Finally, we present a perspective on the development of future research direction and challenges emerging from the layered TMCs nanomaterials towards water splitting electrocatalysts.

\section{Electrochemistry and Hydrogen Evolution Reaction (HER)}

\subsection{Electrochemical Theory and Equations}

To understand the fundamentals of HER, Nernstian potential (under standard conditions) to a normal hydrogen electrode (NHE) is described by:

$$
E_{H E R}=E_{\left(H_{2} / H^{+}\right)}^{0}-\frac{R T}{F}\left(\log \left(\alpha_{H^{+}} / P_{H_{2}}{ }^{1 / 2}\right)\right)=-0.059 \times(\mathrm{pH}) \mathrm{V} \text { vs. NHE }=0 \mathrm{~V} \text { vs. RHE }
$$

On the reversible hydrogen electrode (RHE) scale, the Nernstian potential for the HER is equal to zero regardless of electrolytes used. The HER activity does not start until a sufficient cathodic potential is applied with reaction overpotentials [24]. Taking this into consideration, the potential to drive the HER can be expressed as:

$$
E_{i}=E_{H E R}+i R+\eta
$$

where $\eta$ is the reaction overpotential, which is one of the most important electrode parameters to evaluate its electrochemical performance. Overpotential at a specified apparent current density (normally at $10 \mathrm{~mA} / \mathrm{cm}^{2}$ for HER) is a useful experimental parameter to characterize a given electrode in the working condition, whereas the onset overpotential, often namely as onset potential, refers to the smallest potential where the catalyst starts to catalytically function or the HER process begins. The smaller the overpotential, the higher the energy efficiency. Whereas $i R$ is the ohmic potential drop caused by the flow of current in the ionic electrolyte [25].

The HER process consists of two primary steps in acidic electrolytes [26]. The first step known as the discharge reaction or Volmer reaction in which a proton-coupled electron transfer at the catalyst surface yields an intermediate adsorbed hydrogen atom [27]:

$$
H_{(a q)}^{+}+e^{-} \rightarrow H_{a d s}
$$

Furthermore, hydrogen desorption proceeds through two possible pathways. First, by electrochemical desorption reaction or Heyrovsky reaction in which the adsorbed hydrogen atom can react with another proton from the solution accompanied by a second electron transfer to form molecular hydrogen as:

$$
H_{a d s}+H_{(a q)}^{+}+e^{-} \rightarrow H_{2(g)}
$$

Another possible way for desorption of hydrogen is the recombination reaction or Tafel reaction in which two adsorbed hydrogen atoms form molecular hydrogen as [28]:

$$
H_{a d s}+H_{a d s} \rightarrow H_{2(g)}
$$

To elucidate the operating mechanism on different HER electrocatalysts, the Tafel slope is taken as an indication of the rate determining step [29]. It is defined that the Tafel slope is $118 \mathrm{mV} / \mathrm{dec}$, $39 \mathrm{mV} / \mathrm{dec}$, or $29.5 \mathrm{mV} / \mathrm{dec}$ when the discharge reaction (Volmer reaction), the electrochemical desorption reaction (Heyrovsky reaction), or the recombination reaction (Tafel reaction) is rate determining, respectively. 
It is clear from the above discussion that hydrogen adsorption and desorption on the electrode surface are two successive steps in HER electrocatalysis. However, hydrogen adsorption and desorption are competitive in nature. If catalyst surface has weak bonding strength with hydrogen atoms, it cannot efficiently adsorb the reactant to initiate the HER, whereas a catalyst surface having strong bonding strength would have difficulty in releasing the $\mathrm{H}_{2}$ toward the completion of the HER. Therefore, the ideal HER electrocatalysts should have well balanced hydrogen bonding and releasing properties [18]. It is known that the maximum exchange current density is attained when hydrogen adsorption free energy is close to thermoneutral (i.e., $\Delta \mathrm{G}_{\mathrm{H}}=0$ ). In this respect, Nørskov and co-workers calculated hydrogen adsorption free energy on different transition metals and plotted the HER exchange current density as a function of the calculated free energy [16]. The plotted HER exchange current density as a function of the calculated free energy shows volcano-shaped curve with the peak position close to that of platinum. By following these results, they suggest that $\Delta \mathrm{G}_{\mathrm{H}}$ is a useful descriptor in the selection of new electrocatalysts for hydrogen evolution. The intrinsic per-site activity of a catalyst is also an important metric for further improvement and to guide catalyst development, which is often measured by the turnover frequency (TOF) for each active site. TOF value is related to the activity of each catalytic site of the catalysts. The difficulty in measuring a TOF is not only in determining the rate but also in counting active sites because active sites may not be all identical even for the same catalyst. Practically, for different catalysts, the comparison of the TOFs is only meaningful when the value is taken at the same overpotential.

\subsection{Experimental Conditions}

A common experimental setup for measuring HER activity is a three-electrode system [24]. Here, the working electrode (the catalytic material being tested) is typically applied on a rotating disk, while the reference electrode is $\mathrm{Ag} / \mathrm{AgCl}$ (or occasionally saturated calomel) and the counter electrode is $\mathrm{Pt}$ wire or graphite rod. To ensure the removal of dissolved oxygen, nitrogen bubbling is often continuously applied during measurements. This system allows for reliable testing of HER catalysts with a relatively simple system and a small amount of the tested material. However, it does not accurately reflect all of the challenges in the overall electrolysis of water.

An alternative technique of water electrolysis is to use a polymer exchange membrane (PEM) instead of liquid electrolytes [30]. PEM electrolyzers have the advantage of operating at high current densities and possessing more compact designs but suffer from issues due to higher operating pressures causing cross-permeation. Although this review will primarily focus on catalytic materials tested through the aforementioned three-electrode system, we note that the testing of HER catalysts in PEM electrolyzers is also an active research field [31].

\section{Non-Noble Transition Metals Based Electrocatalysts}

Generally, an ideal HER catalyst should be an earth-abundant material possessing good intrinsic material parameters of a near zero $\Delta \mathrm{G}_{\mathrm{H}}$ and robust stability and extrinsic engineering parameters of the full utilization of catalytically active sites and efficient charge transfer on the non-noble and earth-abundant materials. In this respect, nanostructures of non-noble metals materials and their heterostructures on the conducting support have been addressed for efficient HER electrocatalysts [32,33]. Recently, transition metals alloys and their compounds have been investigated as a promising low-cost and non-noble metal material with high electrocatalytic performances. Within the past few years, transition metal carbides, borides and phosphides have been reported with very promising electrocatalytic activities [34-36]. In 2012, Xile Hu's group have reported catalysts based on transition metal boride (i.e., $\mathrm{MoB}$ ) and transition metal carbide (i.e., $\mathrm{Mo}_{2} \mathrm{C}$ ) with efficient electrocatalytic activity, which are able to rival non-noble metal HER performance working at $\mathrm{pH}=0$ [37]. Moreover, transition metal carbide on conductive carbon nanotubes has shown good HER performance towards by solving the ion transfer problem in electrocatalytic activities [38]. In addition, Shi et al. have reported chemical modification of $\mathrm{Mo}_{2} \mathrm{C}$ via phosphorus doping for efficient 
electrocatalytic activity [39]. Transition metal phosphides, such as $\mathrm{Ni}_{2} \mathrm{P}, \mathrm{FeP}$ and $\mathrm{Co}_{2} \mathrm{P}$, have also been reported for efficient electrocatalytic activity in both acidic and alkaline electrolytes [40-43]. Other phosphides such as nanoparticles of WP and MoP are also showing great promise and recent reports indicate that they have overpotentials around $110 \mathrm{mV}$ or even slightly below when freshly prepared [44,45]. Another approach to get efficient electrocatalysts for HER is to make hybrid structures containing transition metals, carbon and nitrogen atoms [46-48]. Yin et al. have reported Ni-C-N nanosheets with extremely high performance electrocatalyst for HER activity wherein it is indicated that overpotential is $61 \mathrm{mV}$ or even slightly below, which is benchmark for the electrocatalytic activity for HER [46]. As mentioned above, there has been tremendous progress made in the field of acid-stable, nonprecious HER catalysts in the past few years, illustrated by Figure 1, which shows selected highlights from the recent literature.

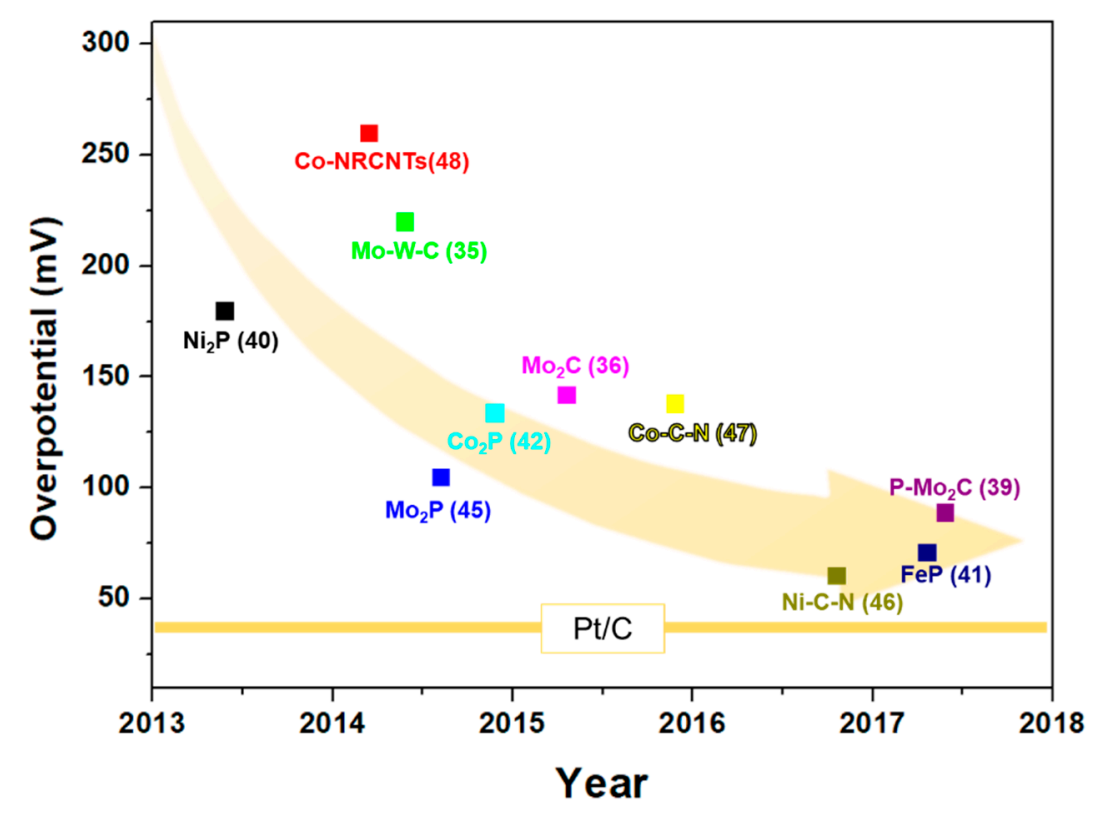

Figure 1. Chronological trend in overpotential at current density of $10 \mathrm{~mA} \mathrm{~cm}^{-2}$ of some reported earth-abundant transition metal based catalysts along with the $\mathrm{Pt} / \mathrm{C}$ catalyst (experimentally measured). Note that all catalysts shown here were measured in $0.5 \mathrm{M} \mathrm{H}_{2} \mathrm{SO}_{4}$ to ensure a fair comparison.

\section{Layered Transition Metal Chalcogenides}

Over the last decade, transition metal chalcogenides (TMCs) have gained growing attention for many applications such as electrocatalysts. To maximize the electrocatalytic properties of TMC materials, there are two primary approaches: increasing the number of active sites through structural engineering (extrinsic) and modifying the chemical composition to reduce the $\Delta \mathrm{G}_{\mathrm{H}}$ (intrinsic) [49]. By changing the structures and compositions (intrinsic and extrinsic) of TMCs, a variety of compounds with different transition metals and chalcogens can be realized. Here we present three different types of TMCs: binary, ternary and quaternary.

\subsection{Binary Transition Metal Chalcogenides}

Binary TMCs are mostly known as transition metal dichalcogenides (TMDs), which contain one type transition metal and one type of chalcogen in their chemical formula. The most well-known example among them is $\mathrm{MoS}_{2}$. MoS 2 naturally occurs as a lamellar hexagonally structure similar to graphite in which the individual S-Mo-S layers weakly interact with each other by van der Waals forces and each layer has a thickness of $\sim 0.64 \mathrm{~nm}$ (shown in Figure 2a) [50,51]. Normally, $\mathrm{MoS}_{2}$ occurs in two different phases, $2 \mathrm{H}$ and 1T. The hexagonal $2 \mathrm{H}$ polytype has two layers per unit cell along the c-axis and 1T-polytype has trigonal in nature, the 2H-type is dominant and more 
stable and 1-T can synthesized by $2 \mathrm{H}$ phase heating (shown in Figure 2a) [52]. There are many methods have been employed to prepare single- and multi-layer binary TMCs. The top-down methods to create 2D materials, which rely on the exfoliation of layered bulk crystals to make few layer flakes, include the mechanical cleavage method [53], chemical intercalation and exfoliation [54-56] electrochemical intercalation and exfoliation [57], liquid phase exfoliation by direct sonication in solvents [52]. Examples of bottom-up approaches are chemical vapor deposition (CVD) growth [58-60] and wet chemical synthesis techniques, such as hydrothermal reactions [61].

(a)

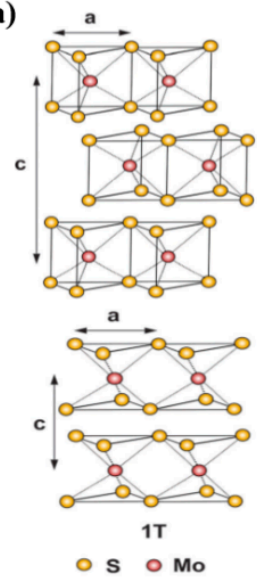

(b)
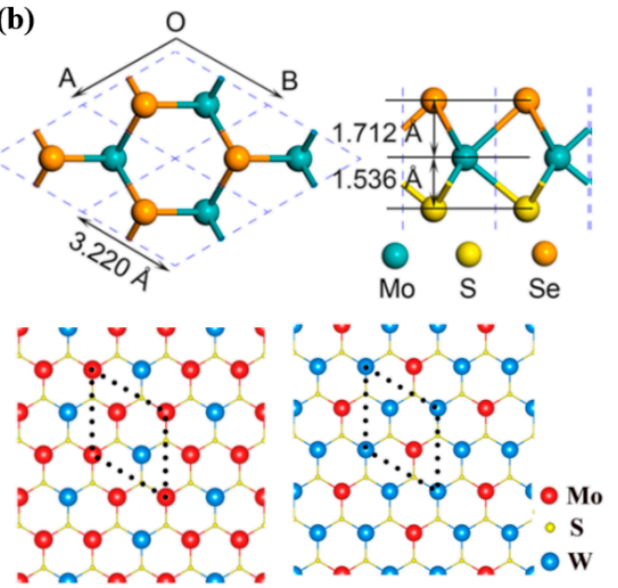

(c)

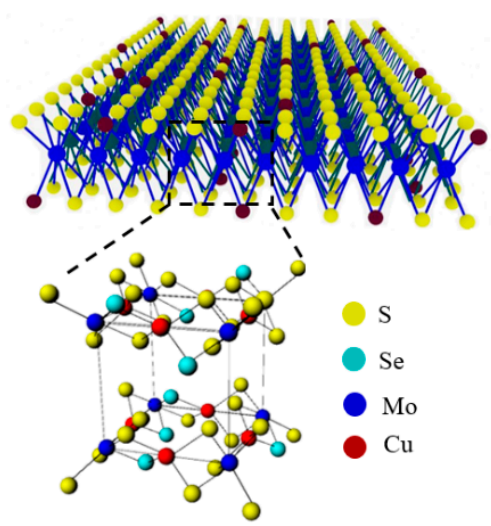

Figure 2. (a) Schematic illustration of the $2 \mathrm{H}$-type structure of binary $\mathrm{MoS}_{2}$ and 1T-type structure of binary $\mathrm{MoS}_{2}$. Reprinted with permission from Reference [52], copyright (2013), Royal Society of Chemistry. (b) Top and side views of the optimized geometry of two anion contains ternary MoSSe and atomic structures of two cation contains ternary $\mathrm{Mo}_{1-\mathrm{x}} \mathrm{W}_{\mathrm{x}} \mathrm{S}_{2}$ atomic structures. Reprinted with permission from Reference [62], copyright (2018), American Chemical Society and Reference [63], copyright (2017), Scientific Reports. (c) Layered and crystal structure of quaternary $\mathrm{Cu}_{2} \mathrm{Mo}\left(\mathrm{S}_{1-\mathrm{y}} \mathrm{Se}_{\mathrm{y}}\right)_{4}$. Reprinted with permission from Reference [64], copyright (2016), Elsevier.

\subsection{Ternary Transition Metal Chalcogenides}

There are two type of ternary TMCs possible, the first contains two types of transition metal and one type of chalcogen in their chemical formula, while the other type contains one transition metal and two types of chalcogen in their chemical compositions. By tuning the atomic ratio of transition metals or chalcogen atoms, researchers have found interesting tunable electronic and optical properties, which would be useful for water splitting electrocatalysts. Recently, Guan et al. have reported ternary MoSSe materials, which have semiconductor properties with a direct band gap of $2.14 \mathrm{eV}$. By theoretical calculation, it is found that MoSSe holds an appropriate band edge alignment with the water redox potentials. The crystal structure of MoSSe is a compromise of binary TMCs $\mathrm{MoS}_{2}$ and $\mathrm{MoSe}_{2}$ (shown in Figure 2b) [62]. Zhang group has reported the synthesis of MoSSe by simple CVD method, which shows extraordinary results in terms of electronic properties [65]. However, $\mathrm{MoS}_{2(1-x)} \mathrm{Se}_{2 x}$ and $\mathrm{WS}_{2(1-\mathrm{x})} \mathrm{Se}_{2 \mathrm{x}}$ alloy nanoflakes have been synthesized by simple solvothermal process $[66,67]$. Meanwhile, the Jeon group has reported synthesis of $\mathrm{MoS}_{\mathrm{x}} \mathrm{O}_{\mathrm{y}}$ by simple CVD method to modulation of band structures of $\mathrm{MoS}_{2}$ [68]. The Fan group has analyzed other type of ternary TMCs that contain two type of transition metal, in which they have shown different ordered and disordered phases of $\mathrm{Mo}_{1-\mathrm{x}} \mathrm{W}_{\mathrm{x}} \mathrm{S}_{2}$ monolayer [63].

\subsection{Quaternary Transition Metal Chalcogenides}

Quaternary TMCs contain two types of transition metal and two types of chalcogen in their chemical formula. Quaternary TMCs can be easily synthesized by a solvothermal method in which one chalcogen atoms are replaced by other type of chalcogen atoms in the structures. The Lee group have synthesized monolayer of $\mathrm{Cu}_{2} \mathrm{Mo}\left(\mathrm{S}_{\mathrm{y}} \mathrm{Se}_{1-\mathrm{y}}\right)_{4}$ quaternary $\mathrm{TMC}$ by a solution processed method for 
extraordinary electrocatalytic activity [64]. The structure of quaternary TMCs can be viewed as layers of transition metals and chalcogen atoms as shown in Figure 2c; the layers are perpendicular to the $c$ direction. Similar to binary TMCs, atoms within the layers of quaternary TMCs are covalently bound, while there are only van der Waals interactions between the layers [69]. Another description of the structure of quaternary TMCs follows from the recognition that the chalcogen lattice can be viewed as a distorted cubic close-packed array of chalcogen atoms (shown in Figure 2c). The two-dimensional structure results from transition metal atom occupation of $3 / 4$ of the tetrahedral holes in alternating layers along the c direction; only $3 \%$ of the total number of tetrahedral holes are filled.

\section{Layered Transition Metal Chalcogenides Based Electrocatalysts for HER}

In 2005, Nørskov et al. applied density functional theory (DFT) calculations to analyze the free energy of hydrogen bonding $\left(\Delta \mathrm{G}_{\mathrm{H}}{ }^{*}\right)$ to layered binary TMC MoS 2 , which revealed that while the basal plane of $\mathrm{MoS}_{2}$ is catalytically inert, its sulfide Mo-edges are active for the HER with suitable $\Delta \mathrm{G}_{\mathrm{H}}{ }^{*}=0.1 \mathrm{~V}$, close to those of several efficient HER electrocatalysts including $\mathrm{Pt}$, nitrogenase and hydrogenase [70]. The theoretical results are confirmed with their experimental findings, that shows nanosized $\mathrm{MoS}_{2}$ clusters on a graphite support indeed have very decent HER activity with an overpotential in the range of $0.1-0.2 \mathrm{~V}$ at $\mathrm{pH}=0$ [70]. The theoretical results show that the best edge configurations correspond to Mo edges covered by $50 \% \mathrm{~S}$ with $\Delta \mathrm{G}_{\mathrm{H}}{ }^{*}=0.06 \mathrm{eV}$ compared to $\mathrm{S}$ edges covered by $100 \% \mathrm{~S}: \Delta \mathrm{G}_{\mathrm{H}}{ }^{*}=-0.45 \mathrm{eV}$ (shown in Figure 3a) [71]. Similar to $\mathrm{MoS}_{2}, \mathrm{WS}_{2}$ edges have also been found to be active with $\Delta \mathrm{G}_{\mathrm{H}}{ }^{*}=-0.04$ and $-0.06 \mathrm{eV}$ for $50 \% \mathrm{~W}$ edges and $100 \% \mathrm{~S}$ edges, respectively.

Additional insights about the active sites (notably the importance of edge sites) can be obtained through spectroscopic techniques. Lassallee-Kaiser et al. [72] used X-ray absorption spectroscopy (XAS) and $\mathrm{MoS}_{3}$ in an acidic environment to assert that Mo(III) units with terminal disulfide ligands are the primary active site in $\mathrm{MoS}_{2}$ and that protonation and reduction of the outer $\mathrm{S}_{2}$ sites is the rate-limiting step for HER. However, some recent works have disputed this conclusion and argued (based on $\Delta \mathrm{G}_{\mathrm{H}}$ calculations) that Mo-edges are more energetically favorable than S-edges for catalytic activity in pristine $\mathrm{MoS}_{2}$, while noting that in cases of doped $\mathrm{MoS}_{2}$ both Mo and S edges contribute to HER activity $[73,74]$. Regardless of the precise mechanism, it is clear that the identification and promotion of edge sites is critical for catalyst development. In $\mathrm{MoS}_{2}$, this can be estimated through Raman spectroscopy, where increased intensity of the $\mathrm{A}^{1} \mathrm{~g}$ out-of-plane mode often indicates additional exposed edge sites [75,76].

Jaramillo et al., who correlated the electrochemical activity and edge length of $\mathrm{MoS}_{2}$ nanoclusters measured by STM, obtained experimental evidence on the crucial role of edges in the HER (Shown in Figure 3b) [77]. Experimentally, exchange current density per active site and the turnover frequency (TOF) (the number of hydrogen molecules/atoms per second being produced per active site per second) for $\mathrm{MoS}_{2}$ edges reaches $0.02 \mathrm{~s}^{-1}$ for compared with $0.9 \mathrm{~s}^{-1}$ for $\mathrm{Pt}$ (111) and rapidly increases with the overpotential (summarized in Figure 3c). Moreover, other sulfur and selenium based TMCs from group 6d transition metal follow same trends as $\mathrm{MoS}_{2}$ and $\mathrm{WS}_{2}$ [70]. The stability of active sites is important for electrocatalysis process. The stability of edges or the basal planes of TMCs are predicted from calculation of adsorption energy of hydrogen on the chalcogen atoms $\left(\Delta \mathrm{G}_{\mathrm{H}-\mathrm{x}}, \mathrm{X}=\mathrm{S}\right.$, Se). Tsai et al. calculated the free energy of hydrogen adsorption on chalcogen atoms to estimate the catalytic activity and the stability of the edges and basal planes of various TMCs (shown in Figure 3e,f) [78]. The values of adsorption energy reveals that the stability with activity on the basal plane is significantly lower in the case of metallic TMCs compared with that of semiconducting TMCs. However, the results indicate that the basal planes of TMCs can be catalytically activated for metallic TMCs with lower free energy of hydrogen adsorption, which open new avenues for improving the HER activity of layered TMCs. 
(a)

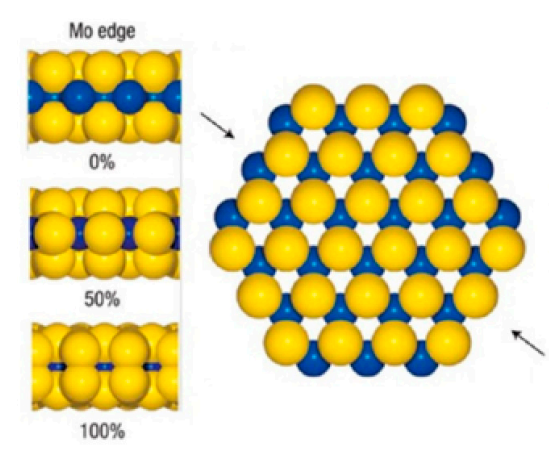

(c)

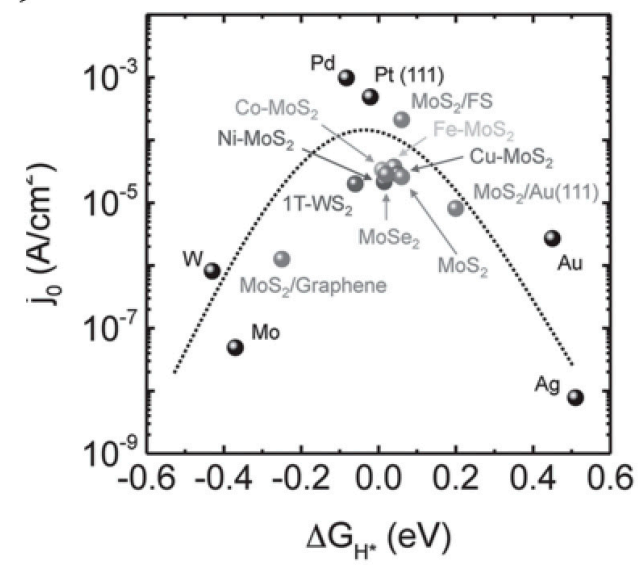

(e)

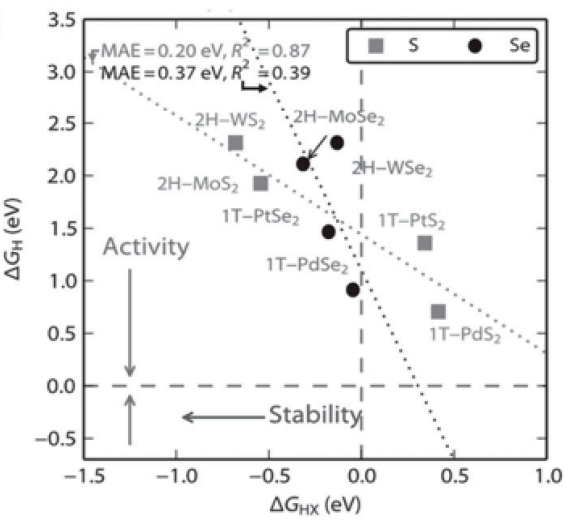

(b)

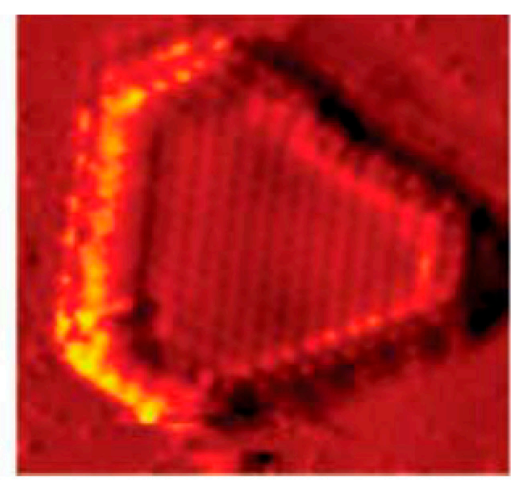

(d)

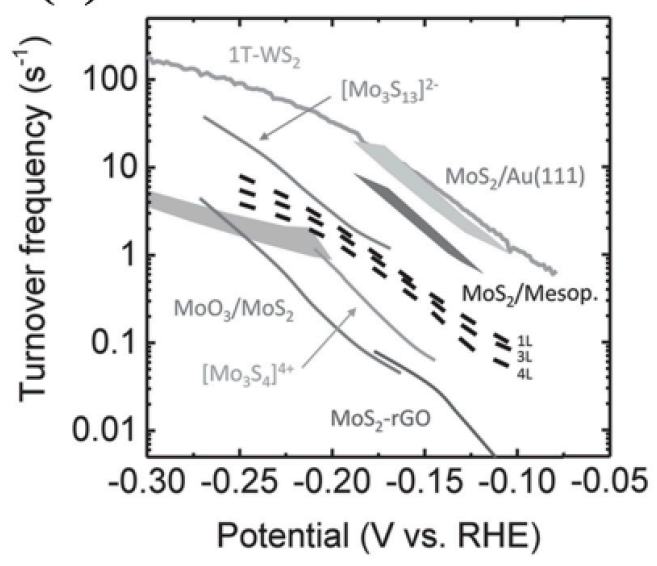

(f)

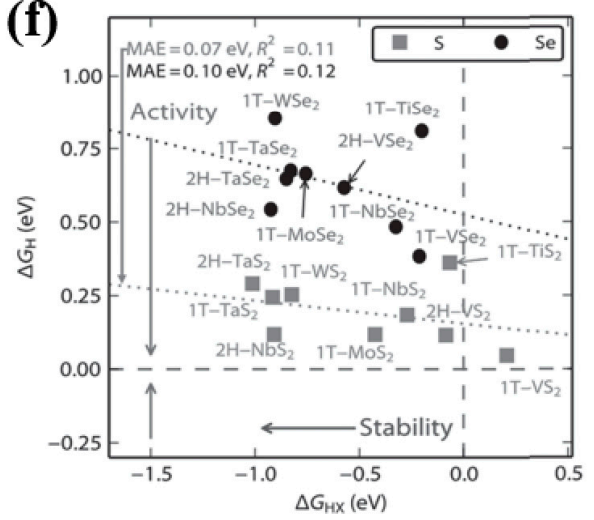

Figure 3. (a) Molecular model of a platelet exposing both Mo and S-edges from top and side view. Reprinted with permission from [79], copyright (2014), American Chemical Society. (b) STM on $\mathrm{MoS}_{2}$ nanoplatelets on $\mathrm{Au}$ (111). Reprinted with permission from Reference [77], copyright (2007), American Association for the Advancement of Science. Thermodynamics of hydrogen adsorption on 2D transition metal dichalcogenides. (c) Sabatier "volcano" plot showing the exchange current density as a function of free energy of hydrogen adsorption of free-standing (FS) $\mathrm{MoS}_{2}$ edges, $\mathrm{MoS}_{2}$ edges on $\mathrm{Au}$ (111), $\mathrm{MoS}_{2}$ edges on graphene, vertically grown $\mathrm{Fe}, \mathrm{Cu}, \mathrm{Ni}$, Co-promoted $\mathrm{MoS}_{2}$ edges, vertically grown $\mathrm{MoS}_{2}$ edges, vertically grown $\mathrm{MoSe}_{2}$ edges, $1 \mathrm{~T} \mathrm{WS_{2 }}$ basal plane and compared with various metals. (d) Evolution of turnover frequency of several catalysts based on transition-metal chalcogenides with overpotential. $(\mathbf{e}, \mathbf{f})$ Plots of $\Delta \mathrm{G}_{\mathrm{H}}{ }^{*}$ : the free energy of hydrogen adsorption as function of $\Delta \mathrm{G}_{\mathrm{HX}}(\mathrm{X}=\mathrm{S}$ or Se): the HX adsorption free energy. (e,f) The evolution is displayed for metallic TMDs (e) and semiconducting TMDs (f). In general the stronger binding of $X\left(\Delta \mathrm{G}_{\mathrm{HX}}<0\right)$, the higher stability of TMDs, the lower the reactivity of TMDs $\left(\Delta \mathrm{G}_{\mathrm{H}}{ }^{*}>0\right)$, the weaker the hydrogen binding. Reprinted with permission from Reference [23], copyright (2016), Wiley-VCH. 


\section{Materials Engineering for Improving Electrocatalytic Activity of TMCs}

\subsection{Edge and Defect Engineering to Enhance the Electrocatalytic Activity of TMCs}

The study of electrochemical activities of TMC edges has opened a new path for increasing the catalytic performances by optimizing the basal plane to edge ratio. In this respect, Xie's group have developed defect-rich $\mathrm{MoS}_{2}$ nanosheets (Figure 4a) and highlighted that their $\mathrm{MoS}_{2}$ sheets contained abundant defects, which resulted in partial cracking of the catalytically inert basal planes, leading to the exposure of additional active edge sites (Figure 4a) [80,81]. The as-obtained defect-rich $\mathrm{MoS}_{2}$ sheets shows an excellent HER activity with an onset potential of $0.12 \mathrm{~V}$ versus RHE and a Tafel slope of $50 \mathrm{mVdec}^{-1}$, as well as a prominent electrochemical durability (Figure 4a). However, it is known that the resistivity through the basal planes of layered multi-layer $\mathrm{MoS}_{2}$ has been measured to be 2200 times larger as compared to the value along the single layer $\mathrm{MoS}_{2}$ nanosheets, which leads to decrease the electrocatalytic activity with increase the number of layers of $\mathrm{MoS}_{2}$ [82]. Yu et al. have reported that the catalytic activity of $\mathrm{MoS}_{2}$ decreases by 4.5 times when adding a layer of $\mathrm{MoS}_{2}$ due to the large potential required for electron hopping between successive layers (shown in Figure 4b) [83].

However, synthesizing vertical or mesoporous $\mathrm{MoS}_{2}$ can tackle the challenge of layer dependence and utilization of active edge sites for electrocatalytic activity. Jaramillo et al. have reported contiguous large-area thin films of a highly ordered double gyroid $\mathrm{MoS}_{2}$ network by templating mesoporous silica films [84]. The as-synthesized highly ordered double gyroid $\mathrm{MoS}_{2}$ exhibits an HER onset overpotential of 150-200 $\mathrm{mV}$ and a Tafel slope of $50 \mathrm{mV}$ per decade. However, Cui et al. have demonstrated vertically aligned $\mathrm{MoS}_{2}$ films by a rapid sulfurization process to convert Mo thin films deposited on various substrates [85]. The vertically aligned $\mathrm{MoS}_{2}$ films show excellent electrocatalytic activity with a large exchange current density of $2.2 \times 10^{-6} \mathrm{~A} \mathrm{~cm}^{-2}$ and a TOF $=0.013 \mathrm{~s}^{-1}$.

\subsection{Support of Conducting Material to Improve Catalytic Activity of TMCs}

The conducting support materials can influence the energy of hydrogen adsorption for TMCs [86]. Normally, if the binding between conducting material and TMCs is strong then hydrogen adsorption will be weak. Tsai et al. have calculated the free energy of hydrogen adsorption for $\mathrm{MoS}_{2}$ supported on various conducting substrates, such as gold, graphene and $M_{0} S_{2}$, which shows that $\Delta \mathrm{G}_{\mathrm{H}}{ }^{*}$ for the Mo edge on graphene or gold is significantly higher compared to the freestanding Mo-edge [86]. Although $\Delta \mathrm{G}_{\mathrm{H}}{ }^{*}$ reveals useful insights for HER electrocatalytic activity, it provides only a partial picture of HER process at the heterostructures of conducting substrate and TMCs [23]. The electrical conductivity is an important parameter to enhance electrocatalytic activities. In poorly conducting materials, an additional potential is required to drive electrons more efficiently to the active sites for electrocatalytic activity. This is a major drawback for group $6 \mathrm{~d}$ TMCs, which typically consist of a semiconducting trigonal prismatic structure. The intrinsic conductivity $6 \mathrm{~d}$ TMCs can be enhanced via doping or by growing the nanosheets on a conducting surface. Li et al. have synthesized $\mathrm{MoS}_{2}$ nanoparticles on the conducting reduced graphene oxides (r-GO) surface [87]. As seen in Figure 4c,d, the introduction of rGO enhances significantly catalytic activity of $\mathrm{MoS}_{2}$, showing a small onset potential of $0.1 \mathrm{~V}$ versus RHE and a low Tafel slope of $41 \mathrm{mV} \mathrm{dec}{ }^{-1}$. Similarly, Yang et al. have reported a layered $\mathrm{WS}_{2}$ on $\mathrm{rGO}$ with enhanced electrocatalytic activity [88]. The growth of TMCs on graphene enables a strong anchoring of nanosheets on the graphene basal plane, which improves the electrical conductivity and leads to a dramatic decrease of the charge-transfer resistance [88]. Efforts have been made to enhance electrocatalytic activity of TMCs by materials engineering via making heterostructures and different architectures of TMCs but structural instability and difficulty in correlation of morphology control or atomic scale modification with improved HER activity make the strategy less useful [89]. 

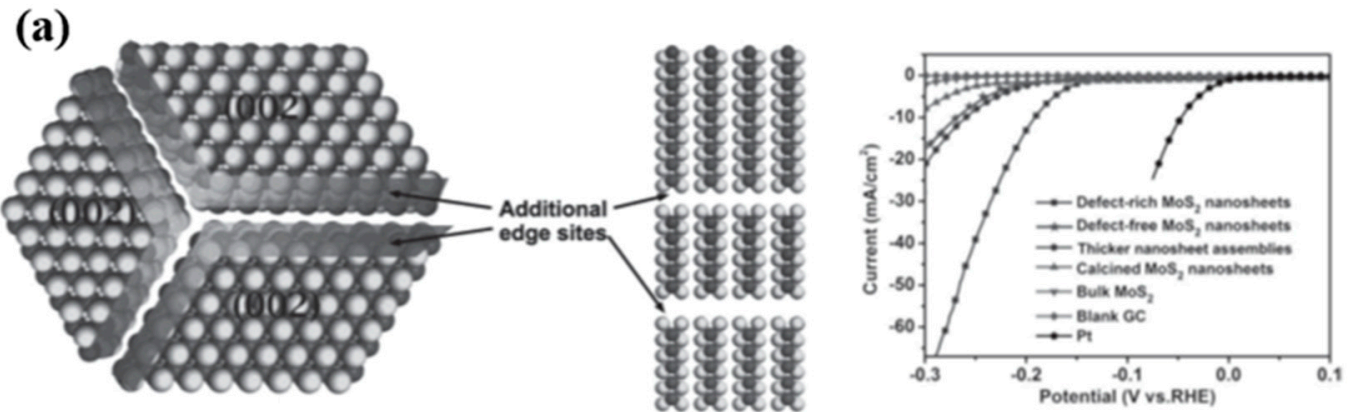

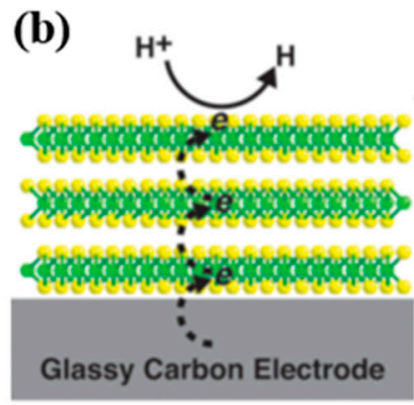

(c)

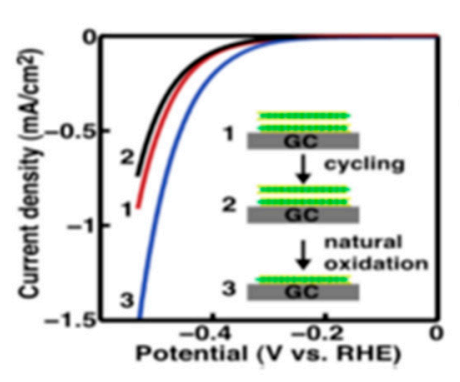

(d)
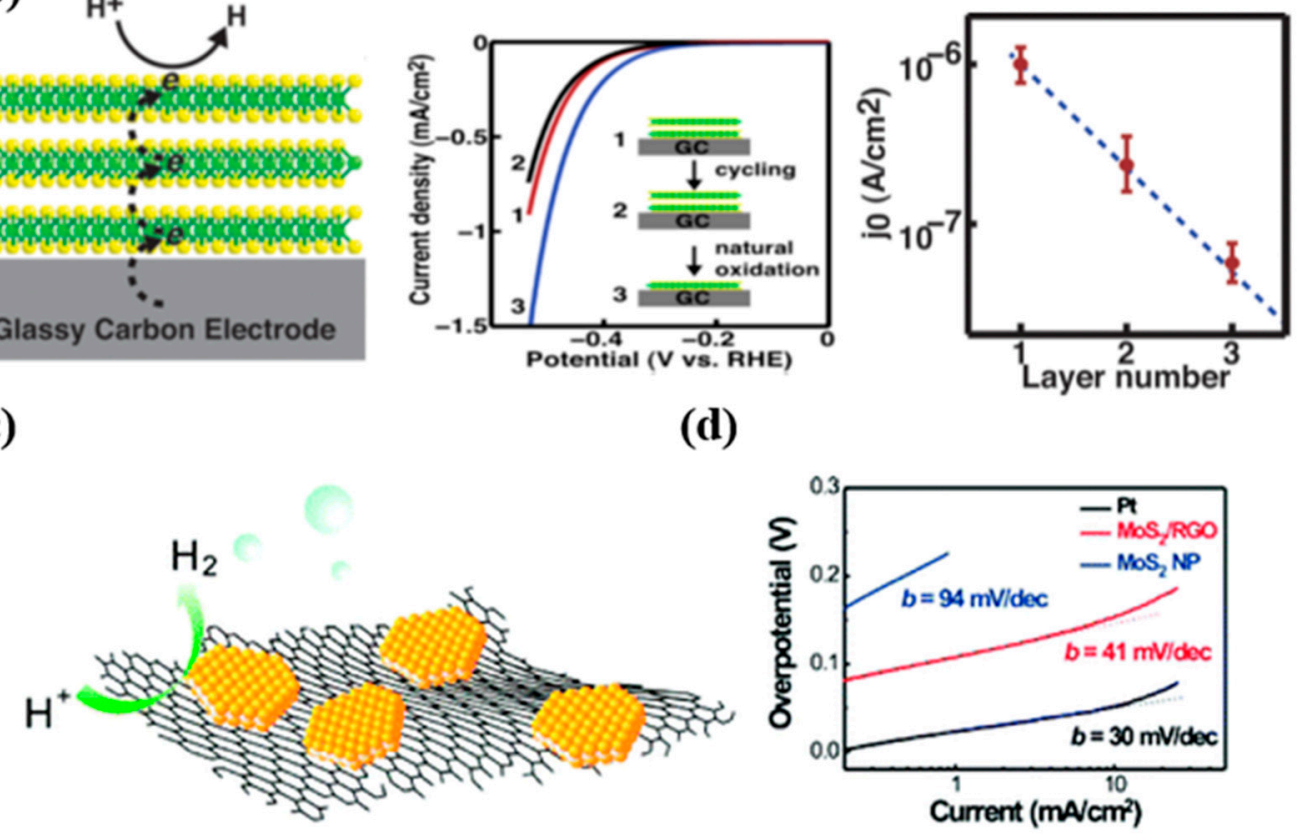

Figure 4. (a) Schematic representation of defect-rich $\mathrm{MoS}_{2}$ nanosheets and polarization curves obtained from $\mathrm{MoS}_{2}$ nanosheets with various densities of defects. Reprinted with permission from Reference [81], copyright (2013) Wiley-VCH. (b) Schematic illustrating the electron hopping between the layers of $\mathrm{MoS}_{2}$ and evolution of the exchange current density of $\mathrm{MoS}_{2}$ with increasing number of layers. Reprinted with permission from Reference [83], copyright (2014), American Chemical Society. (c) Illustration for the $\mathrm{MoS}_{2}$ nanoparticles decoration on conductive graphene layer. (d) Tafel plots for the $\mathrm{MoS}_{2}$ nanoparticles and $\mathrm{MoS}_{2}$ nanoparticles decorated graphene samples along with Pt. Reprinted with permission from Reference [87], copyright (2011), American Chemical Society.

\subsection{Design of Hierarchical Structure to Further Improve the Catalytic Activity of TMCs}

In principal, the further performance improvement of catalysts can be achieved in two aspects, which include the increase of their intrinsic activity of single/multi-active sites and the upturn of their surface area. The former one has been discussed above through the synergistic effect among multicomponents towards the adjustment of their active sites. The latter one can be achieved by increasing the exposure surface area of catalysts in the electrolyte. Normally, the higher surface-to-volume ratio is favorable for exposing the active sites. However, the agglomerated nanoparticles often bring alone adverse effects on the electrocatalytic performance, for instance the low utilization of catalysts and high charge transfer resistance. Simultaneously, the coated electrocatalyst layer on the electrode is prone to peel off from the substrate during vigorous gas evolution under a high current density, which significantly limits the practical applications. Hence, the design and synthesis of hierarchical structure is necessary that can solve the above problems effectively by offering a seamless integration. At the same time, the use of hierarchical structure also provides many other 
advantages, such as improving the penetration of electrolyte and releasing gas bubbles efficiently because of the associated increasing amount of free space there.

Particularly, hierarchically nanostructured NiFeSe can be prepared as an efficient OER catalyst using Prussian blue as the template [89]. The preparation process is divided into two steps. $\mathrm{Ni}-\mathrm{Fe}$ Prussian blue analog is first etched via ammonia and then followed by selenylation at $\mathrm{N}_{2}$ atmosphere. As chemical etching time increases, the morphologies evolve from nanocubes and nanodisks to nanocages, as seen in Figure 5a. The final product of NiFeSe nanocages shows the excellent OER performance that affords a current density $10 \mathrm{~mA} / \mathrm{cm}^{2}$ at a small overpotential of $240 \mathrm{mV}$. The excellent performance can be attributed to the larger electrochemically active surface area, which benefits from the high electrolyte-catalyst contact interface area provided by the open and hollow structure.

Typically, the hierarchical structure can be mainly divided into three categories, including the polyhedral shape with special structures (e.g., star-shaped, concave tetrahedral, etc.), the unusual morphological features formed via the interaction of nanoparticles (e.g., core-shell, segments and branches, etc.) and the integration of multiple dimensional subunits in the nanoscale (e.g., zero dimensional nanoparticles, one dimensional nanowires or nanotubes, two dimensional nanosheets, etc.). Until now, there are many excellent reviews on the design of hierarchical structure [90-92]. In terms of TMC served as electrocatalysts, most of the hierarchical structure are belonged to the third configuration discussed above, in which they are mostly prepared via the solvothermal method. In this regard, the following section will particularly focus on the recent research progress of hierarchical structure from the perspective of solvothermal synthesis.

\subsection{Support/Template Synthesis for Hierarchical Structures}

The preparation of hierarchical structure by template-assisted methods can be rather straightforward in the concept. In general, the template-assisted synthesis can be divided into three kinds, in which they are the hard-template method, soft-template and self-template schemes.

For the hard-template method, the introduced template with high uniformity is usually employed as physical scaffolds to create continuous voids in the final product, which can be subsequently removed. Specifically, there are four key steps involved: (1) template preparation, (2) template surface functionalization, (3) target material coating and (4) template removal. Typical hard template materials consist of $\mathrm{SiO}_{2}$, carbon sphere, anodized aluminum oxide (AAO), metal-based structures with specific shapes, 2D materials and many others. For example, multiscale $\mathrm{MoS}_{2}$ foam was successfully prepared by using $\mathrm{SiO}_{2}$ as the hard template [93]. Detailed TEM characterization reveals that the $\mathrm{MoS}_{2}$ foam possess abundant spherical voids, where $\mathrm{MoS}_{2}$ nanosheets are also vertically aligned around the mesopores with a large fraction of edge sites exposed. This study can evidently demonstrate many advantages of hierarchical structure via overall consideration of the mass transport and the accessibility towards HER. Besides, hierarchical transition-metal dichalcogenide nanosheets can as well be prepared from 2D nanosheets. Zhang's group reported the hierarchical TMC nanosheets $\left(\mathrm{MoS}_{2}\right.$ and $\mathrm{WS}_{2}$ ) via a one-pot heating treatment of melamine and metal precursors, as seen in Figure 5b [94]. At first, the polymerization of melamine into carbon nitride during thermal treatment can direct the horizontal growth of TMD nanoplates. Then, the subsequent decomposition of carbon nitride can guide the vertical growth of hierarchical TMC nanosheets. In any case, although uniform shapes and morphologies of the hierarchical structure can be readily prepared via hard-template methods, the tedious and complex preparation process would limit their practical applications. Importantly, homogeneous nucleation often takes precedence over heterogeneous nucleation on the surface of the template in solution, which would eventually induce the failure of the warp structure. 
(a)

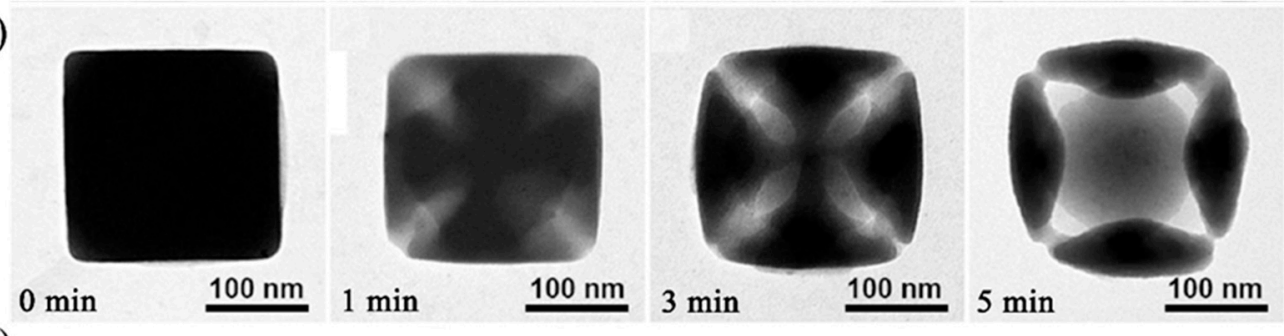

(b)
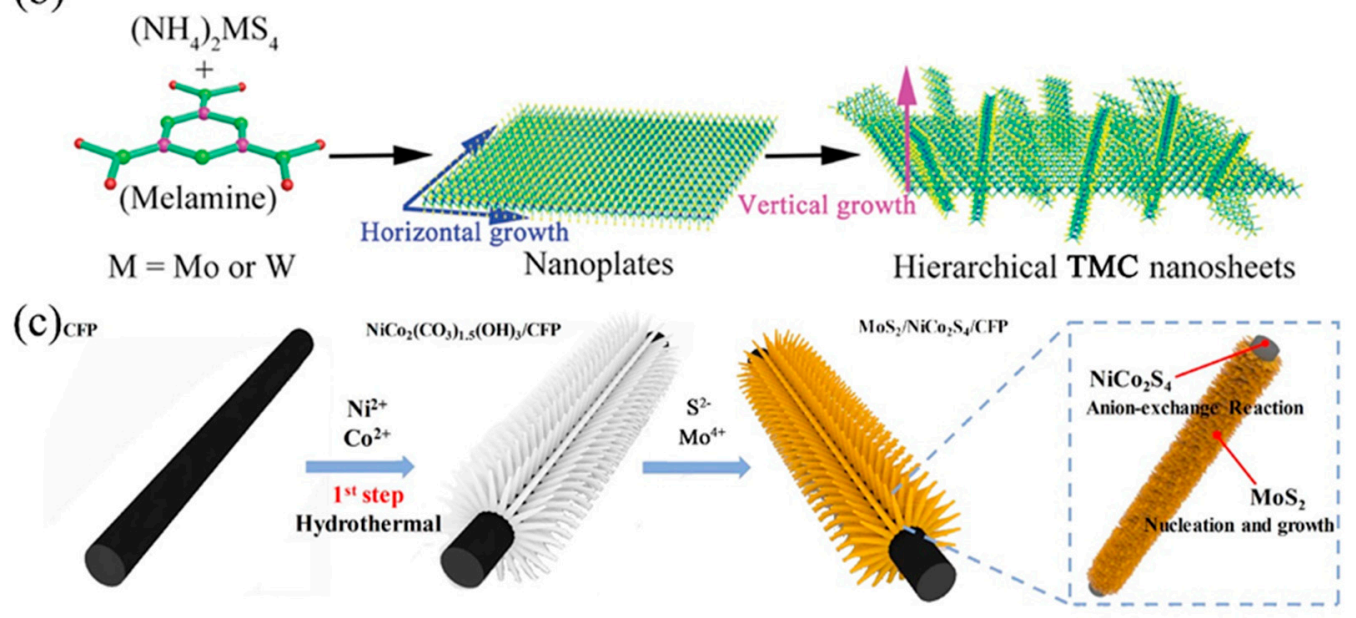

Figure 5. (a) The evolution of hierarchical Ni-Fe-Se nanocages prepared via chemical etching. Reprinted with permission from Reference [89], copyright (2017), Wiley-VCH. (b) Procedure of hierarchical TMC nanosheets using carbon nitride as the template. Reprinted with permission from Reference [94], copyright (2015), Wiley-VCH. (c) Hierarchical $\mathrm{MoS}_{2} / \mathrm{NiCo}_{2} \mathrm{~S}_{4} / \mathrm{CFP}$ structure prepared via anion-exchange reaction. Reprinted with permission from Reference [95], copyright (2018), Elsevier.

On the other hand, soft templates mainly refer to the templates formed by organic surfactants, polymers, viruses, bacteria and bubbles and so forth. These materials can self-assemble into the ordered structures under certain conditions, such as micelles or reverse micelles, emulsions or micro-emulsion, vesicles and such. The target substance or its precursor is typically nucleated on the surface of the template composed of these ordered structures. For example, coral-like CoSe could be prepared via two-step solvothermal reaction. Flower-like $\mathrm{Co}(\mathrm{OH})_{2}$ could be synthesized using Pluronic P123 (polyethylene-polypropylene glycol) as surfactants and then followed by anion exchange [96]. The prepared coral-like CoSe electrode exhibit a low overpotential of $295 \mathrm{mV}$ to drive a current density of $10 \mathrm{~mA} \mathrm{~cm}^{-2}$ with a small Tafel slope of $40 \mathrm{mV} \mathrm{dec}^{-1}$. Notably, the removal of soft templates is easier than that of the hard templates; therefore, the associated template damage to the successively obtained hierarchical structure can then be minimized. At the same time, the shell structure is often porous, which is beneficial to the exposure of active sites in the inner hole. However, as similar with hard template methods, the surface properties of the template and the interaction between the template and the precursor have a decisive effect on the formation of hierarchical structures. This process is inevitably complicated, which limits the application domains of these soft and hard template methods.

In contrast, the self-template method is a scheme of synthesizing micro/nanoscale templates and then transforming them into hierarchical structures. This way, the template not only acts as a physical support but also directly participates in the formation of the shell layer. Metal hydroxides, metal oxide and metal-organic framework (MOF) are all popular templates, which can be directly converted into a shell or as a precursor to the shell [97-102]. For example, Lou's group reported $\mathrm{CoSe}_{x} \mathrm{~S}_{2-x} @ \mathrm{Co}(\mathrm{OH})_{2}$ hierarchical nanotubes as an efficient OER catalysts [103]. Separate selenylation and sulfurization on the $\mathrm{Co}(\mathrm{OH})_{2}$ via the anion-exchange reactions play an important role on the formation of hierarchical structures. It is also noted that MOF usually has the stable and uniform 
shape, which the composition can be controlled rationally via selecting proper precursors and post-treatment. CoSe2@Carbon nanotubes derived from MOF were prepared successfully as an efficient HER catalyst [104]. The final product possess the uniform morphology with an average size of $300 \mathrm{~nm}$ and as well with the surface surrounded by carbon nanotubes. This unique hierarchical structure can bring the excellent electrocatalytic performance, including a low onset potential of $40 \mathrm{mV}$ and a small Tafel slope of $82 \mathrm{mV} \mathrm{dec}^{-1}$ in $0.5 \mathrm{M} \mathrm{H}_{2} \mathrm{SO}_{4}$ solution. Yu's group also reported the $\mathrm{Ni}-\mathrm{Co}-\mathrm{MoS}_{2}$ nanoboxes through the reaction between Prussian blue and ammonium thiomolybdate under solvothermal condition [98]. Well-defined cubic voids inside the nanoboxes are surrounded by ultrathin $\mathrm{MoS}_{2}$ nanosheets, which are clearly observed through TEM characterization. The same group as well constructed the NiS nanoframes using Prussian blue as the self-template scheme with the similar method [97].

Furthermore, direct growth of active nanomaterials onto the three-dimensional conductive substrate is commonly adopted to prepare hierarchical structure. In this case, the clear solution contained with precursors of active material and the substrate are prepared. The hierarchical structure can be simply obtained via controlling the temperature and reaction time. Until now, nickel foam, iron foam, carbon paper and carbon fiber are all suitable candidates here. Evidently, huge amounts of work have already proved that the introduction of 3D substrate would substantially improve the corresponding electrocatalytic performance [105-107]. To be specific, our group prepared readily the ultrathin P-doped $\mathrm{MoS}_{2}$ nanosheets on carbon cloth [108]. The synergistic effect between large surface area and modified active sites would make the P-doped (3.3 at.\%) $\mathrm{MoS}_{2}$ nanosheets exhibiting the significantly lower overpotentials of 133 and $189 \mathrm{mV}$ to drive the current densities of 20 and $100 \mathrm{~mA}$ $\mathrm{cm}^{-2}$, respectively. Except these commercial substrates, metal oxide/hydroxide nanowire arrays on the 2D substrate can also a good choice here [109]. Arrays of $\mathrm{ZnSe} / \mathrm{MoSe}_{2}$ nanotubes on fluorine doped tin oxide (FTO) glass substrates are synthesized and employed as an efficient HER catalyst [110]. The arrays of $\mathrm{ZnO}$ on FTO can also be functioned as 3D template for the subsequent modification. All these can illustrate the versatility of all template-assisted methods for the formation of efficient hierarchical electrocatalysts.

\subsection{Self-Organized Nanostructures}

Different from the support/template method, the hierarchical structure synthesized via self-assembly schemes can be commonly controlled by a careful selection of solvents, reaction time, temperature, metal precursors and so on $[95,111,112]$. An example of a hierarchical structure formed by hydrothermal anion exchange method is shown in Figure $5 \mathrm{c}$. The formation of these hierarchical structures can be mainly divided into two stages: the nucleation stage and the growth stage. Uniquely, it is effective to control the thermodynamic and kinetic parameters to tune these two stages in order to reach the morphological control here [113]. Particularly, the hierarchically nanostructured $\mathrm{MoS}_{2}$ nanosheets can be prepared as a HER catalyst in water-ethylene glycol mixture solution under solvothermal condition. As the ethylene glycol concentration increases, the morphologies evolve from nanoflowers and nanosheets to nanoflake aggregates. TEM characterization also confirm that the nanosheets possess the rich in-plane edges reaching a low onset potential of $87 \mathrm{mV}$ and a Tafel slope of $41 \mathrm{mV} \mathrm{dec}^{-1}$, indicating the usefulness of these self-organized nanostructures for high-performance hierarchical electrocatalysts.

\section{Chemical Modifications for Improving Electrocatalytic Activity of TMCs}

After the initial research into binary TMCs showed promising results for electrocatalysts, a natural new direction of study was opened into ternary TMC systems featuring more complex blends. These can include binary TMCs that undergo doping or other post-synthesis treatments to introduce another component, or bottom-up synthesis methods that utilize varying precursor ratios to tune the composition. In this section, we will explore current results and trends regarding double anion, double cation and quaternary (i.e., double anion and double cation) TMC electrocatalysts. 


\subsection{Double Anion Ternary Transition Metal Chalcogenides as Electrocatalysts for Water Splitting}

Before they were widely studied as catalysts, double-anion TMCs such as mixed sulfur/selenium or partially oxidized sulfide had already seen research in other electronic or optical applications. However, their potential for HER catalysts was unique due to the possibility for these ternary blends to activate the basal plane in TMCs. Xie et al. [80] was among the first to publish major research into double anion TMCs for HER. By controlling the synthesis temperature of a bottom-up synthesis reaction for $\mathrm{MoS}_{2}$ flakes, the oxygen content was controlled, with lower temperature reaction conditions leading to increased oxygen content. The flakes showing an increasing degree of disorder as the content increased, eventually becoming fully amorphous. The best performing sample $(2.28$ at. $\% \mathrm{O}$ and $35-40 \%$ disordered) showed a Tafel slope of $55 \mathrm{mV} / \mathrm{dec}$, a dramatic improvement over the pure MoS2 value of $81 \mathrm{mV} / \mathrm{dec}$. This showed the potential of double anion TMCs and the importance of inducing disorder/defects in the basal plane.

A similar strategy of defect creation and partial oxidation was used by Tao et al. [114], where the effects of $\mathrm{Ar}$ and $\mathrm{O}_{2}$ plasma on $\mathrm{CVD} \mathrm{MoS}_{2}$ were studied. The formation of these defects as well as localized $\mathrm{MoO}_{3}$ was attributed to improve HER properties and the best sample $\left(\mathrm{O}_{2}\right.$ plasma treated for $720 \mathrm{~s}$ ) was shown to have a Tafel slope of $105 \mathrm{mV} /$ dec compared to $160 \mathrm{mV} / \mathrm{dec}$ for the pristine $\mathrm{MoS}_{2}$.

Although this type of defect creation and oxidation can successfully activate the basal planes of TMCs, another issue for TMCs is the charge transport from the electrocatalysts to the electrode, an issue that could be worsened by the amorphous or oxygen-rich regions of TMCs due to their lower electrical conductivity. To solve this issue, Zhang et al. [115] created amorphous $\mathrm{MoS}_{\mathrm{x}} \mathrm{Cl}_{\mathrm{y}}$ supported by graphene. By using a low-temperature CVD process, the $\mathrm{MoCl}_{5}$ precursor was only partially sulfurized and did not crystallize. These composite samples showed outstanding HER properties, with the amorphous sample on vertical graphene requiring only $-160 \mathrm{mV}$ at $10 \mathrm{~mA} \mathrm{~cm}{ }^{-2}$ and having a Tafel slope of only $46 \mathrm{mV} / \mathrm{dec}$.

Another popular strategy for double anion TMC catalysts is to substitute Se for $\mathrm{S}$ to induce a similar increase of active sites. Xu et al. [67] synthesized $\mathrm{WS}_{2(1-x)} \mathrm{Se}_{2 \mathrm{x}}$ nanotubes by a transforming $\mathrm{WO}_{3}$ nanowires via a chemical vapor method, with the $\mathrm{S} / \mathrm{Se}$ ratio controlled by varying the elemental precursors. Although the Tafel slope of the mixed-phase $\mathrm{WS}_{2(1-\mathrm{x})} \mathrm{Se}_{2 \mathrm{x}}$ was not shown to be improved compared to pure $\mathrm{WSe}_{2}(105 \mathrm{mV} / \mathrm{dec}$ and $99 \mathrm{mV} / \mathrm{dec}$, respectively), it was noted that the overpotential and current exchange density of $\mathrm{WS}_{2(1-\mathrm{x})} \mathrm{Se}_{2 \mathrm{x}}$ was superior to pure $\mathrm{WS}_{2}, \mathrm{WSe}_{2}$, or $\mathrm{WO}_{3}$.

Gong et al. [66] also created a mixed S/Se TMC through a bottom-up method using $\mathrm{MoCl}_{5}$ and varying the elemental S/Se added, as seen in Figure 6b. Here, an even ratio of $\mathrm{S}$ and Se (MoSSe) was shown to be the most efficient electrocatalyst. The work reported a Tafel slope of $48 \mathrm{mV} / \mathrm{dec}$ the overpotential at $10 \mathrm{~mA} \mathrm{~cm}{ }^{2}$ of $164 \mathrm{mV}$, as well as $93 \%$ current density retention after 8000 cycles. The authors noted that previous theoretical work had suggested that sulfide Mo edges have a positive hydrogen adsorption energy $\left(\Delta \mathrm{G}_{\mathrm{H}}=80 \mathrm{meV}\right)$ [70], while selenide Mo edges have a negative adsorption energy $\left(\Delta \mathrm{G}_{\mathrm{H}}=-140 \mathrm{meV}\right)$ [116]. It was therefore suggested that the alloyed composition could reduce this value to near thermoneutral.

Molybdenum sulfoselenide was also studied by Zhou et al. [117] by growth over a 3D porous $\mathrm{NiSe}_{2}$ foam (Figure 6c). The underlying foam provided high surface area and a metallic electrical conduction pathway, while the $\mathrm{MoS}_{2(1-x)} \mathrm{Se}_{2 x}$ particles with vertically aligned layers provided the catalytically active sites. The Tafel slope and overpotential at $10 \mathrm{~mA} \mathrm{~cm}{ }^{-2}$ were reported to be $42 \mathrm{mV} / \mathrm{dec}$ and $69 \mathrm{mV}$, respectively, both of which were much better than pure $\mathrm{MoS}_{2}$ over $\mathrm{NiSe}_{2}$ foam. 

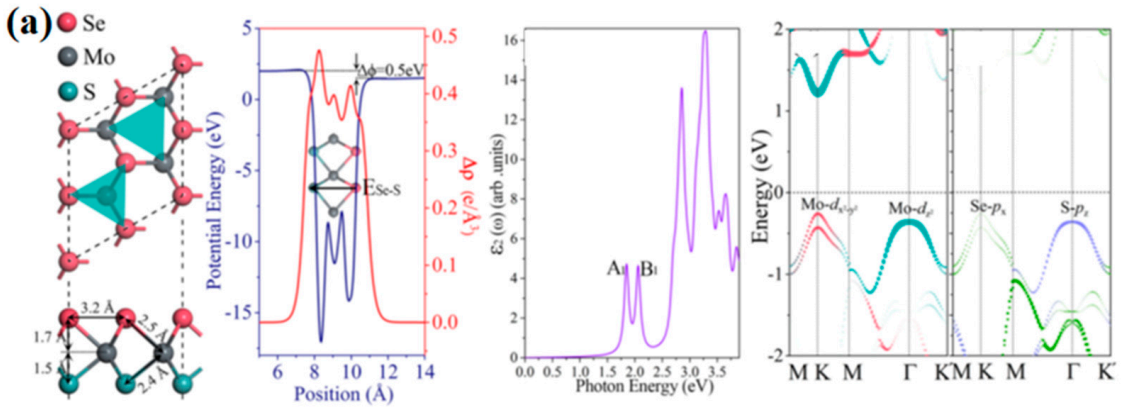

(b)
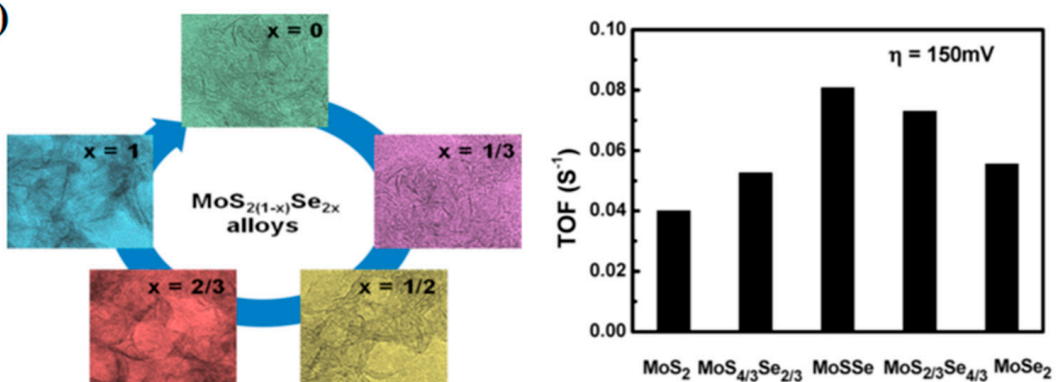

(c)

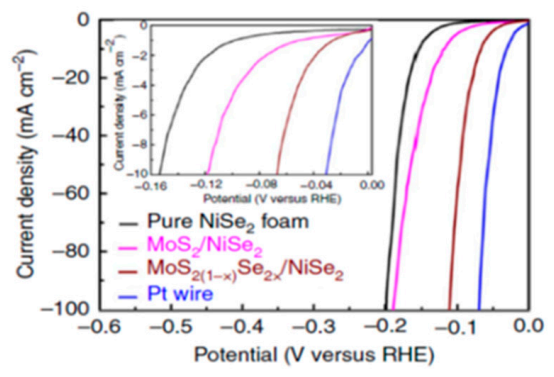

(d)

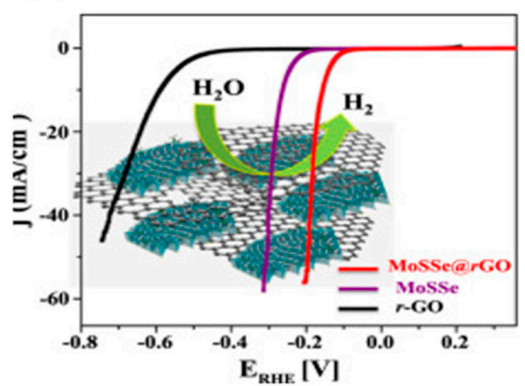

Figure 6. (a) Crystal structures of two anion contain MoSSe with changing the proton energy and band diagrams. Reprinted with permission from Reference [118], copyright (2017), American Chemical Society. (b) Schematic illustration of MoSSe alloy formation and turnover frequency at $\eta=150$ Mv for different compositions. Reprinted with permission from Reference [66], copyright (2015), American Chemical Society. (c) The polarization curves recorded on $\mathrm{MoS}_{2(1-x)} \mathrm{Se}_{2 x} / \mathrm{NiSe}_{2}$ foam hybrid, $\mathrm{MoS}_{2} / \mathrm{NiSe}_{2}$ foam hybrid and pure NiSe ${ }_{2}$ foam electrodes compared with a Pt wire [117]. (d) By taking advantage of the electrostatic attraction between the two oppositely charged nanosheets, MoSSe@rGO composite materials are obtained exhibiting superior electrocatalytic activity and stability for the HER allowing a current density of $5 \mathrm{~mA} \mathrm{~cm}^{-2}$ at a low overpotential of only $135 \mathrm{mV}$. Reprinted with permission from Reference [119], copyright (2016), Elsevier.

Although S and Se are far more widely researched, Te is another chalcogen that can be utilized to create efficient HER catalysts. Kosmala et al. [120] synthesized $\mathrm{MoSe}_{2-x} \mathrm{Te}_{\mathrm{x}}$ films through molecular beam epitaxy and reported a Tafel slope and overpotential at $10 \mathrm{~mA} \mathrm{~cm}{ }^{-2}$ of $62 \mathrm{mV} / \mathrm{dec}$ and $410 \mathrm{mV}$, respectively. The authors showed that the system contains many metallic twin boundaries, thermodynamically stable defects which can increase catalytic activity. Interestingly, the ideal composition was found to be Te-rich ( $\left.\mathrm{MoSe}_{0.12} \mathrm{Te}_{1.79}\right)$ and it was also noted that the pristine $\mathrm{MoTe}_{2}$ was far more catalytically active that the pristine $\mathrm{MoSe}_{2}$ prepared under the same conditions. This is a result that contradicts previous computational [121] and experimental [122] research that had suggested tellurides would not be as intrinsically catalytically active as sulfides or selenides. Therefore, research into telluride-based TMC catalysts may be an avenue worth further exploration.

Other anions explored for substitution into TMCs include nitrogen, which was studied by Sun et al. [123] to create $\mathrm{N}$-doped $\mathrm{WS}_{2}$ nanosheets through a one-step sol-gel process using $\mathrm{WCl}_{6}$ and thiourea followed by post-annealing in $\mathrm{H}_{2}$. The work demonstrated a Tafel slope of $70 \mathrm{mV} / \mathrm{dec}$ and no 
significant loss of current density over $10 \mathrm{~h}$ at $200 \mathrm{mV}$. Like other double anion TMCs, the result was attributed to increased active sites due to defect formation.

Phosphorus substitution was recently studied by Liu et al. [124] using a bottom-up method to create P-doped $\mathrm{MoS}_{2}$ nanosheets. A doping level of up to 5 at.\% was achieved and this sample showed outstanding catalytic properties, including a Tafel slope of $34 \mathrm{mV} / \mathrm{dec}$, which is extremely close to the reference $\mathrm{Pt} / \mathrm{C}$ benchmark catalyst $(30 \mathrm{mV} / \mathrm{dec}$ ). Interestingly, the performance enhancement was attributed to not only the increased active sites but also an improvement in the electrical conductivity due to increased charge carriers. In addition, the expanded interlayer distance of the P-doped sample $(0.91 \mathrm{~nm})$ compared to the reference $\operatorname{MoS}_{2}(0.65 \mathrm{~nm})$ was asserted to lower the $\Delta \mathrm{G}_{\mathrm{H}}$ value.

Due to the wide availability of both dopant anions and synthesis methods available to create double anion TMCs, it is likely that research in this direction will continue to progress. It is possible that future works will combine double anion active materials with the conductive supports previously discussed, such as MoSSe/rGO catalysts shown in Figure 6d [118]. It is worth noting that all work reported to date has used methods that cannot produce any sort of regular ordering or arrangement of the substituting atoms. It is possible that periodic or ordered double anion structures, such as the "Janus" TMCs suggested by recent theoretical works $[62,116,125]$ would yield unique electrocatalytic properties. In these structures, one side of the transition metal (W or Mo) is sulfurized while the other is selenide (illustrated in Figure 7a). However, the only reported synthesis method [65] for these structures is a complex and multi-step process, which may limit research into their potential for HER catalysts. We also predict that strategies utilizing naturally high surface area starting materials such as Ni foam (shown in Figure $7 \mathrm{~b}, \mathrm{c}$ ) will receive growing interest in the near future.
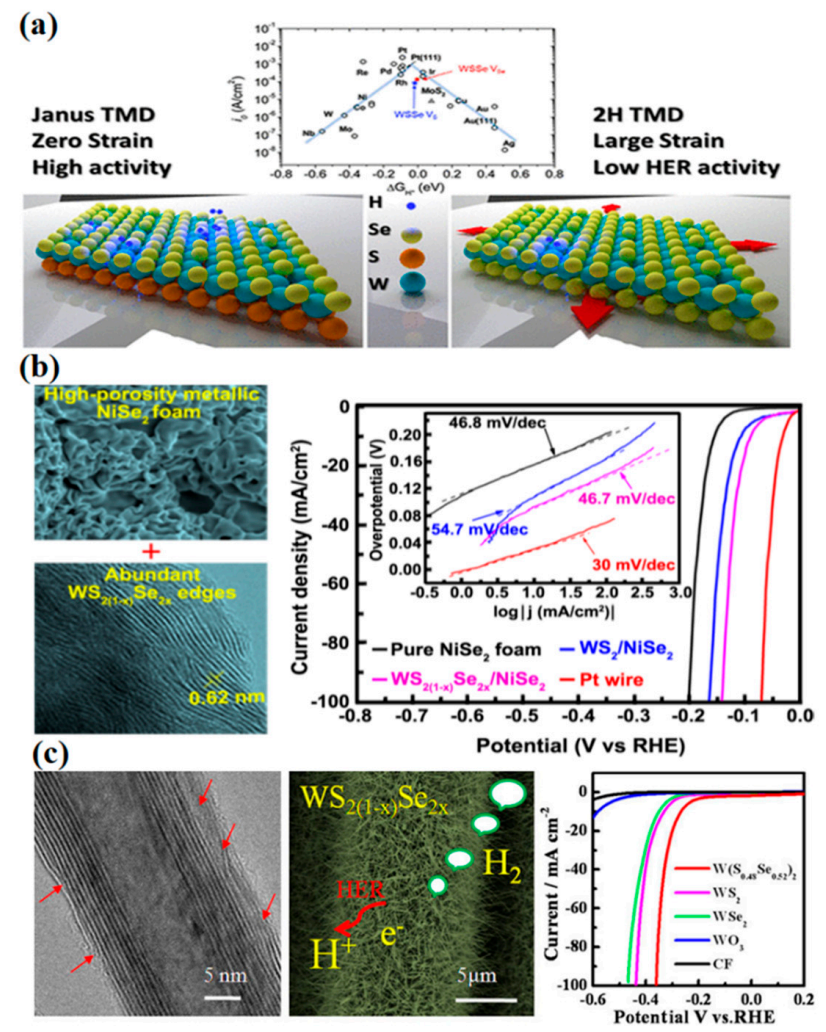

Figure 7. (a) Schematic for WSSe with $\Delta \mathrm{G}_{\mathrm{H}}$ "volcano" plot, the illustration shows that strain free Janus TMDs possess better HER activities. Reprinted with permission from [125], copyright (2018), American Chemical Society. (b) TEM of $\mathrm{WS}_{2(1-x)} \mathrm{Se}_{2 x}$ particles with a 3D porous metallic NiSe2 foam and corresponding polarization curves recorded on $\mathrm{WS}_{2(1-x)} \mathrm{Se}_{2 x} / \mathrm{NiSe}_{2}$ foam. (c) TEM of $\mathrm{WS}_{2(1-x)} \mathrm{Se}_{2 \mathrm{x}}$ nanotubes and corresponding polarization curves recorded on $\mathrm{WS}_{2(1-x)} \mathrm{Se}_{2 \mathrm{x}}$ in comparison with $\mathrm{WS}_{2}$. Reprinted with permission from Reference [67], copyright (2014), American Chemical Society. 


\subsection{Double Cation Ternary Transition Metal Chalcogenides as Electrocatalysts for Water Splitting}

Like double anion TMC catalysts, double cation catalysts have been extensively studied as HER catalysts. In many ways, the core goals are similar in both cases, namely, to disrupt the normally inactive basal plane and create addition active sites through defect or strain formation. However, because the transition metal atoms are generally not adsorption sites for layered TMC materials, many works have suggested that the benefit of double cation TMCs may be more attributable to electron density and local field effects, as illustrated in Figure 8a [63].

Li et al. [111] synthesized $\mathrm{Mo}_{(1-\mathrm{x})} \mathrm{W}_{\mathrm{x}} \mathrm{S}_{2}$ using a hydrothermal method with $\mathrm{Na}_{2} \mathrm{MoO}_{4} \cdot \mathrm{H}_{2} \mathrm{O}$ and $\mathrm{Na}_{2} \mathrm{WO}_{4} \cdot \mathrm{H}_{2} \mathrm{O}$ in varying ratios and analyzed the effect of cation ratio on HER performance. The $\mathrm{Mo}_{0.85} \mathrm{~W}_{0.15} \mathrm{~S}_{2}$ composition showed the best electrocatalytic properties, including a Tafel slope of $89 \mathrm{mV} / \mathrm{dec}$ and stability demonstrated for 1000 cycles. Using DFT calculations, it was shown that the band gap of $\mathrm{MoWS}_{2}(0.88 \mathrm{eV})$ was smaller than that of $\mathrm{MoS}_{2}(1.14 \mathrm{eV})$ and that $\mathrm{W}$ atoms create an "electron-rich" configuration through directional transfer. It was asserted that this electronic modification improves the conductivity and therefore decreases the charge transfer resistance.

(a)
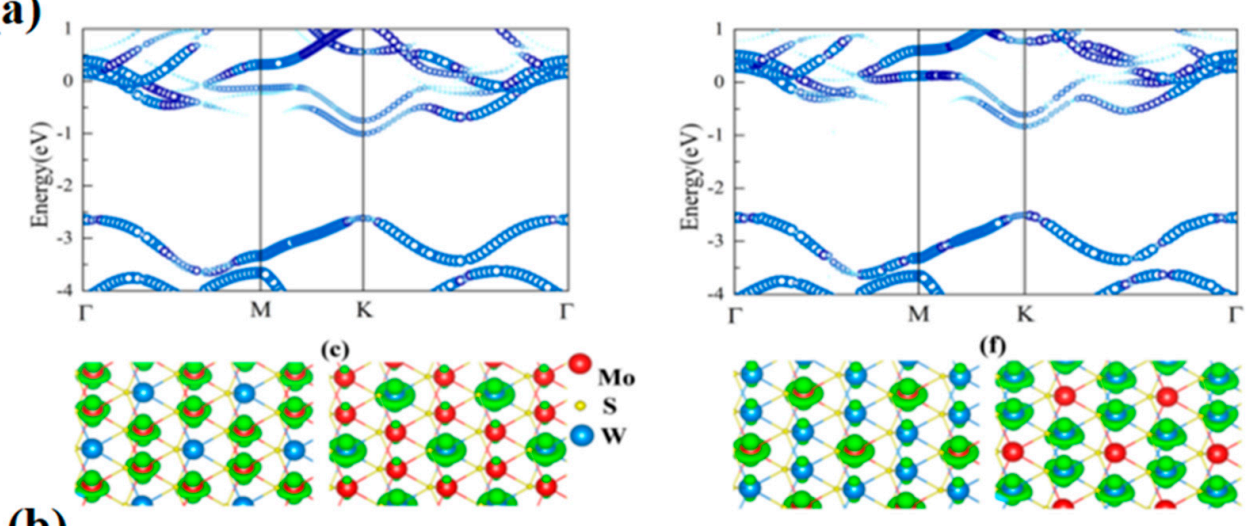

(b)

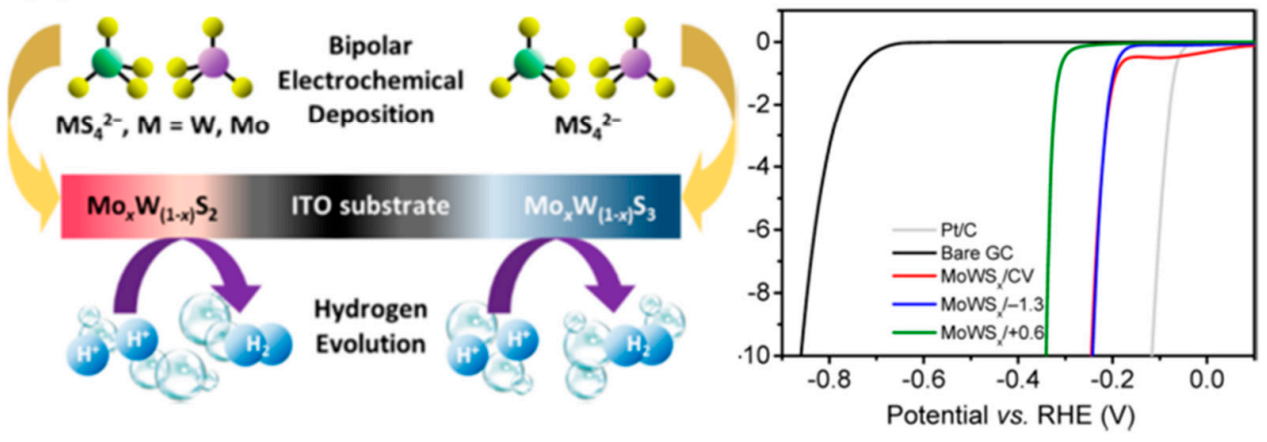

Figure 8. (a) Unfolded energy band of two cations contains ternary $\mathrm{Mo}_{1-\mathrm{x}} \mathrm{W}_{\mathrm{x}} \mathrm{S}_{2}$. Reprinted with permission from Reference [63], copyright (2017), Scientific Reports. (b) Schematic illustration for the formation of $\mathrm{Mo}_{1-\mathrm{x}} \mathrm{W}_{\mathrm{x}} \mathrm{S}_{2}$ and $\mathrm{Mo}_{1-\mathrm{x}} \mathrm{W}_{\mathrm{x}} \mathrm{S}_{3}$ and corresponding polarization curves recorded on $\mathrm{Mo}_{1-\mathrm{x}} \mathrm{W}_{\mathrm{x}} \mathrm{S}_{2}$ and $\mathrm{Mo}_{1-\mathrm{x}} \mathrm{W}_{\mathrm{x}} \mathrm{S}_{3}$. Reprinted with permission from Reference [126], copyright (2017), American Chemical Society.

Tan and Pumera [126] synthesized composition-graded, sulfur-deficient MoWS . The material was initially synthesized through electrodeposition using $\left(\mathrm{NH}_{4}\right)_{2} \mathrm{MoS}_{4}$ and $\left(\mathrm{NH}_{4}\right)_{2} \mathrm{WS}_{4}$ dissolved in $0.1 \mathrm{M} \mathrm{KCl}$ solution (Figure 8b). Because these were synthesized using bipolar deposition, two distinct compositions were designated based on whether the deposition was cathodic (creating $\operatorname{Mo}_{x} W_{(1-x)} S_{2}$ ) or anodic (creating $\mathrm{Mo}_{\mathrm{x}} \mathrm{W}_{(1-\mathrm{x})} \mathrm{S}_{2}$ ). The Tafel slope and overpotential at $10 \mathrm{~mA} \mathrm{~cm}{ }^{-2}$ for the samples were $45.7 \mathrm{mV} / \mathrm{dec}$ and $315 \mathrm{mV}$ for the cathodic sample and $50.5 \mathrm{mV} / \mathrm{dec}$ and $278 \mathrm{mV}$ for the anodic sample. The even $\mathrm{Mo} / \mathrm{W}$ ratio and high exposed surface are of the small particles were cited as the primary reasons for the increased performance compared to pure $\mathrm{MoS}_{2}$ or $\mathrm{WS}_{2}$. 
Several other works have reported similar Mo/W mixtures for HER catalysts, including Li et al. [127] reporting MoWS on carbon cloth and Gan et al. [128] demonstrating $\mathrm{Mox}_{\mathrm{y}} \mathrm{W}_{2}$ supported by pyrolytic carbon. These works consistently report that the mixed systems outperform the single-cation TMCs but the ideal Mo/W ratio for HER activity is different for each study. This indicates that differences in processing conditions or supporting structures may greatly affect the ideal composition.

Many other metals have been studied for TMC catalysts in the form of cation dopants. Shi et al. [129] studied $\mathrm{MoS}_{2}$ doped with a variety of metals: $\mathrm{Co}, \mathrm{Cu}, \mathrm{Fe}, \mathrm{Ni}$ and $\mathrm{Zn}$. $\mathrm{Zn}$ was shown to be the best dopant, with a Tafel slope of $51 \mathrm{mV} / \mathrm{dec}$ representing a dramatic improvement over the pristine $\mathrm{MoS}_{2}$ value $(101 \mathrm{mV} / \mathrm{dec})$. The improvement was attributed to both energy level modification and morphological effects induced by $\mathrm{Zn}$ doping.

However, not all dopant cations have shown improved catalytic performance. Chua et al. [130] reported that both niobium and tantalum doing in $\mathrm{MoS}_{2}$ and $\mathrm{WS}_{2}$ failed to improve the HER performance and the undoped $\mathrm{MoS}_{2}$ showed the best overpotential at $10 \mathrm{~mA} \mathrm{~cm}{ }^{-2}$ of any of the tested samples. This result was particularly notable because the authors confirmed the increased presence of the $1 \mathrm{~T}$ metallic phase after doping, which had been shown to be beneficial in other HER studies [131,132]. In addition, Tsai et al. [133] had computationally predicted that many types of cation dopants, including $\mathrm{Ta}$ and $\mathrm{Nb}$, would bring the $\Delta \mathrm{G}_{\mathrm{H}}$ value closer to thermoneutral and benefit HER properties.

Although not technically 'double' cation catalysts, Askari et al. [134] synthesized two mixed cation systems-MoWCoS and MoWCuS—by a hydrothermal method using sodium molybdate, sodium tungstate and either cobalt chloride or copper chloride as precursors. When hybridized with reduced graphene oxide, the MoWCoS showed particularly strong HER properties, with the Tafel slope and overpotential reported to be $38 \mathrm{mV} / \mathrm{dec}$. It was asserted that the CoS phases present within the material create new interfaces and introduce additional defects, greatly increasing the catalytic activity.

A more unusual TMC system was studied by Zhan et al. [135]: $\mathrm{Ag}_{2} \mathrm{WS}_{4}$ prepared through a low-temperature $\left(60^{\circ} \mathrm{C}\right)$ ion-exchange reaction using $\left(\mathrm{NH}_{4}\right) \mathrm{WS}_{4}$ and $\mathrm{AgNO}_{3}$ precursors. The sample showed a Tafel slope of $62 \mathrm{mV} / \mathrm{dec}$ and was stable for $24 \mathrm{~h}$. Edge-sharing of $\mathrm{AgS}_{4}$ and $\mathrm{WS}_{4}$ tetrahedra was asserted to create numerous active sites. We do note that the use of silver undermines the typical goal of "noble-metal free catalysts" that is often stated in HER research. However, the price of silver is still far less than that of typical benchmark noble metal for electrocatalytic reactions (i.e., $\mathrm{Pt}$ and $\mathrm{Ru}$ ).

Zhou et al. [136] created another TMC based on a rarely-studied metal by coating $\mathrm{MoS}_{\mathrm{x}}$ on $\mathrm{NbS}_{2}$ nanoflakes. The initial $\mathrm{NbS}_{2}$ over glassy carbon (GC) was synthesized by CVD followed drop casting over glassy carbon (GC) and coating with ammonium thiomolybdate to create $\mathrm{MoS}_{\mathrm{x}} @ \mathrm{NbS}_{2} / \mathrm{CG}$ electrocatalysts. The sample showed solid HER performance, with a Tafel slope of $43.2 \mathrm{mV} / \mathrm{dec}$ and an overpotential of $-164 \mathrm{mV}$ at $-10 \mathrm{~mA} \mathrm{~cm}^{-2}$. The authors also noted that the performance at high current densities was particularly strong; the overpotential at $-200 \mathrm{~mA} \mathrm{~cm}{ }^{-2}(-233 \mathrm{mV})$ was claimed to be even lower than that of the commercial $\mathrm{Pt} / \mathrm{C}$ catalyst $(-274 \mathrm{mV})$. It was shown that the interface region creates numerous $\mathrm{S}$ vacancies in $\operatorname{MoS}_{\mathrm{x}}$, which lowers the $\Delta \mathrm{G}_{\mathrm{H}}$ value.

In addition to $\mathrm{W}$ and Mo-based TMCs, many other metals have been studied for use in HER catalysts. Amin et al. synthesized $\mathrm{CoNi}_{2} \mathrm{Se}_{4}$ via electrodeposition for overall water splitting (i.e., OER and HER). The vacancy-ordered spinel structure was shown to be a highly efficient OER catalyst but the HER properties were not as impressive: the overpotential was reported as $220 \mathrm{mV}$ at $10 \mathrm{~mA} \mathrm{~cm}^{-2}$.

Like mixed anion TMC HER catalysts, it is likely that this direction will also continue to see a wide range of research interest. However, the exact role of the mixed cation seems to be slightly less clear than that of mixed anion systems, with many different suggested mechanisms claimed to be responsible for performance enhancements (electron density modulation, 2H/1T phase transformation, morphological effects, etc.). For this reason, more fundamental studies and detailed investigations into the roles of specific cation dopants would undoubtedly be beneficial for future HER research. 


\subsection{Quaternary Transition Metal Chalcogenides as Electrocatalysts for Water Splitting}

Because both mixed anion and mixed cation systems have shown better HER properties than their binary reference materials, combining these two approaches to create quaternary systems was a natural next step in electrocatalyst research. Compared to the double anion and double cation works, this approach has not yet seen as much published research but it is likely to grow in popularity as the standards for electrocatalytic performance increase and researchers looks for new ways to innovate.

Tiwari et al. [64] synthesized a quaternary TMC through a bottom-up direct reaction using $[\mathrm{Cu}(\mathrm{MeCN})]\left(\mathrm{BF}_{4}\right),\left(\mathrm{NH}_{4}\right)_{2}\left[\mathrm{MoS}_{4}\right]$ and diphenyl diselenide (DPDS) (Figure 9a). By adjusting the DPDS concentration, the ratio of $\mathrm{S}$ to $\mathrm{Se}$ could be tuned, creating $\mathrm{Cu}_{2} \mathrm{Mo}\left(\mathrm{S}_{\mathrm{y}} \mathrm{Se}_{1-\mathrm{y}}\right)_{4}$. The sample with $\sim 3$ at.\% Se doping showed the best HER properties: $52 \mathrm{mV} / \mathrm{dec}$ Tafel slope and $-170 \mathrm{mV}$ overpotential at $10 \mathrm{~mA} \mathrm{~cm}^{-2}$. DFT calculations suggested that similar to Se substitution in previously studied ternary TMCs, Se substitution increases the number of active sites and reduces the $\Delta \mathrm{G}_{\mathrm{H}}$ value.

(a)
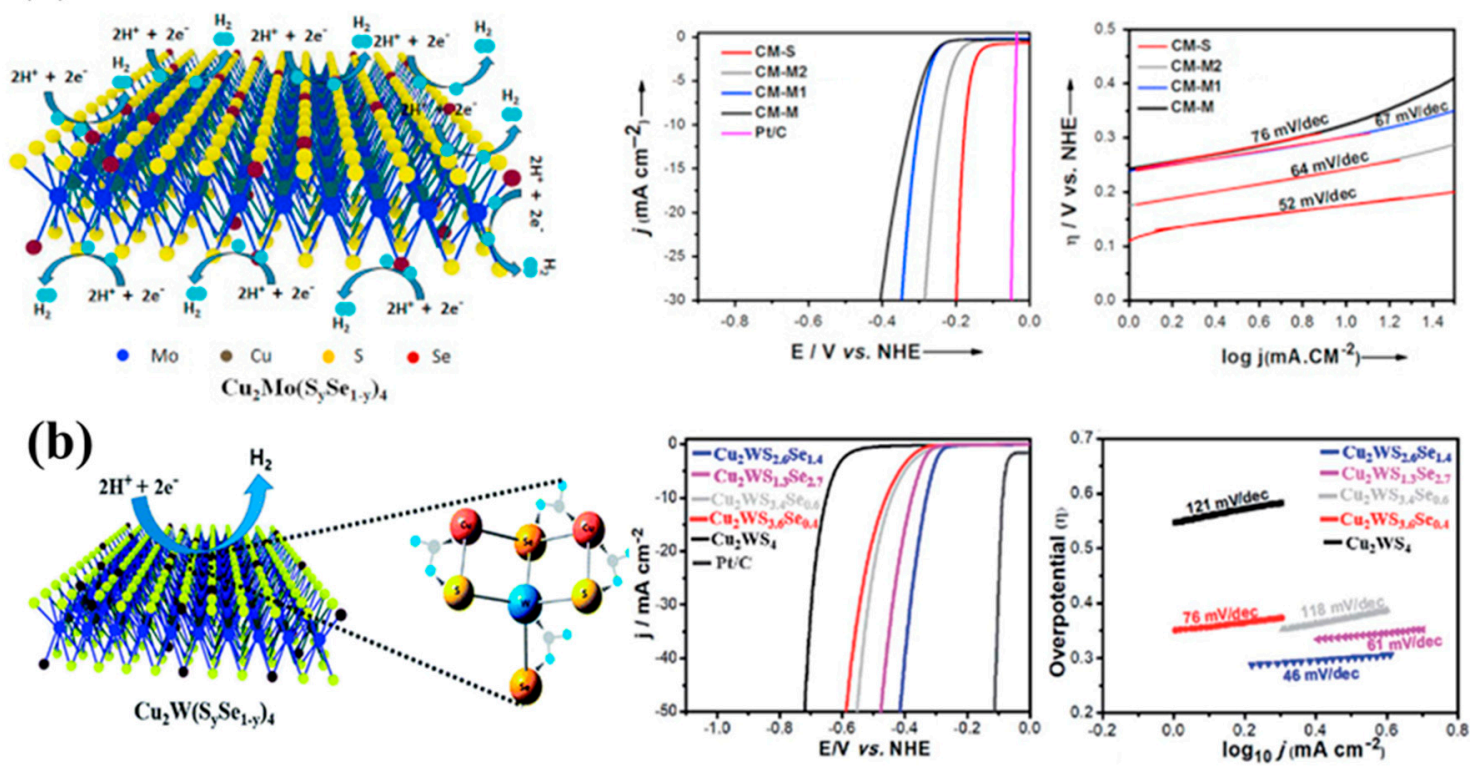

Figure 9. (a) Schematic illustration of HER activity on single layer $\mathrm{Cu}_{2} \mathrm{Mo}\left(\mathrm{S}_{1-y} \mathrm{Se}_{\mathrm{y}}\right)_{4}$ and corresponding polarization curves and Tafel plots for single and multi-layer $\mathrm{Cu}_{2} \mathrm{Mo}\left(\mathrm{S}_{1-\mathrm{y}} \mathrm{Se}_{\mathrm{y}}\right)_{4}$. Reprinted with permission from Reference [64], copyright (2016), Elsevier. (b) Schematic illustration of HER activity on $\mathrm{Cu}_{2} \mathrm{~W}\left(\mathrm{~S}_{1-\mathrm{y}} \mathrm{Se}_{\mathrm{y}}\right)_{4}$ and corresponding polarization curves and Tafel plots for $\mathrm{Cu}_{2} \mathrm{~W}\left(\mathrm{~S}_{1-\mathrm{y}} \mathrm{Se}_{\mathrm{y}}\right)_{4}$. Reprinted with permission from Reference [137], copyright (2018), Royal Society of Chemistry.

Later, Kim et al. [138] used a similar method to synthesize $\mathrm{Cu}_{2} \mathrm{MoS}_{4}$ and decorated the surface with $\mathrm{MoSe}_{2}$ nanodots. The nanodot size and concentration was optimized and the authors found that the smallest diameter nanodots $(30 \mathrm{~nm})$ were most effective at enhancing HER performance due to their higher surface area. The optimized sample showed a Tafel slope of $74.7 \mathrm{mV} / \mathrm{dec}$ and an overpotential of $166 \mathrm{mV}$ at $\mathrm{mA} \mathrm{cm}^{-2}$, with the mechanism of enhancement claimed to be the additional active sites created by the $\mathrm{MoSe}_{2}$ nanodots.

Recently, Tiwari et al. [137] also used the previously reported selenium doping technique [64] in the $\mathrm{Cu}_{2} \mathrm{WS}_{4}$ system to synthesize $\mathrm{Cu}_{2} \mathrm{~W}\left(\mathrm{~S}_{\mathrm{y}} \mathrm{Se}_{1-\mathrm{y}}\right.$ ) (Figure $9 \mathrm{~b}$ ). The Tafel slope and overpotential at $10 \mathrm{~mA} \mathrm{~cm}{ }^{-2}$ for the best sample $\left(\mathrm{Cu}_{2} \mathrm{WS}_{1.3} \mathrm{Se}_{2.7}\right)$ were reported to be $46 \mathrm{mV} / \mathrm{dec}$ and $320 \mathrm{mV}$, respectively. It was concluded through $\mathrm{XRD}$ and Raman analysis that the Se substation created chemical strain in the lattice, lowering the $\Delta \mathrm{G}_{\mathrm{H}}$ value and creating a greater number of active sites. 
A thorough study of the composition compositional effects using Mo, W, S and Se was performed by Gong et al. [139], where 25 different compositions were synthesized through a solution-phase method. The work identified $\mathrm{WS}_{2}, \mathrm{Mo}_{0.67} \mathrm{~W}_{0.33} \mathrm{~S}_{2}, \mathrm{Mo}_{0.5} \mathrm{~W}_{0.5} \mathrm{SSe}$ and $\mathrm{Mo}_{0.33} \mathrm{~W}_{0.67} \mathrm{~S}_{1.33} \mathrm{Se}_{0.67}$ as the best performing compositions and noted that in general the ternary or quaternary catalysts outperformed their binary counterparts. A summary of the electrocatalytic performance of all 25 compositions is shown in Figure 10.

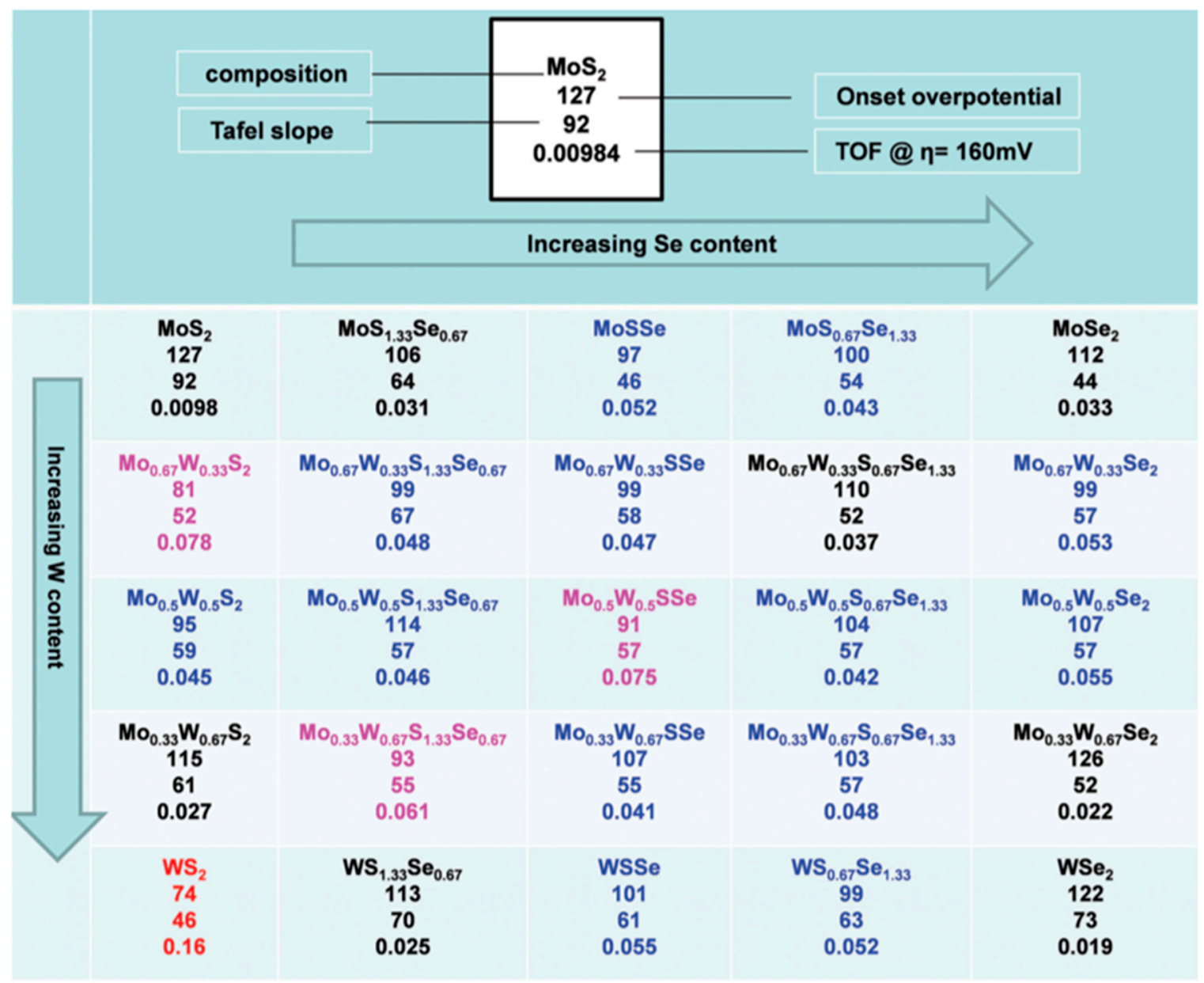

Figure 10. Summarizing the onset overpotential, Tafel slope and TOF @ $\eta=160 \mathrm{mV}$ of different compositions. The red color labels compositions with TOF $>0.1 \mathrm{~s}^{-1}$; the magenta color labels compositions with $0.06<\mathrm{TOF}<0.1 \mathrm{~s}^{-1}$; the blue color labels compositions with $0.04<\mathrm{TOF}<0.06 \mathrm{~s}^{-1}$. Adapted with permission from Reference [139], copyright (2016), Wiley-VCH.

Another quaternary system was reported by Wang et al. [140] by using a carbothermal ammonia reduction strategy over nickel foam to synthesize MoNiNC. The optimized structures delivered a Tafel slope of $65 \mathrm{mV} / \mathrm{dec}$ and overpotential at $10 \mathrm{~mA} \mathrm{~cm}{ }^{-2}$ of $110 \mathrm{mV}$. Although not technically a chalcogenide, work is notable because DFT calculations revealed that both the double metal (Mo and $\mathrm{Ni}$ ) as well as the double anion ( $\mathrm{N}$ and $\mathrm{C}$ ) weaken the bond strength between the active site and the adsorbed reactive intermediate, resulting in improved HER properties. This proves that the synergistic effects of quaternary TMCs is a research avenue worth further development and exploration. A summary of the performance data of binary, ternary and quaternary catalysts can be found in Table 1 . 
Table 1. Performance data of various catalysts, showing the overpotential at $10 \mathrm{~mA} \mathrm{~cm}{ }^{-2}\left(\eta_{10}\right)$ and Tafel slopes.

\begin{tabular}{|c|c|c|c|c|c|}
\hline Type & Composition & Structure & $\eta_{10}(\mathrm{mV})$ & Tafel (mV/dec) & Ref. \\
\hline \multirow{5}{*}{ Binary } & $\mathrm{WSe}_{2}$ & Nanotubes & 365 & 99 & [67] \\
\hline & $\mathrm{MoS}_{2}$ & Nanoparticles@rGO & 130 & 41 & [87] \\
\hline & $\mathrm{MoS}_{2}$ & \multirow{2}{*}{ Hierarchical nanosheets } & 167 & 70 & \multirow{2}{*}{ [94] } \\
\hline & $\mathrm{WS}_{2}$ & & 157 & 60 & \\
\hline & $\mathrm{MoSe}_{2}$ & 3D hierarchical & 317 & 47 & [107] \\
\hline \multirow{6}{*}{ Ternary (double anion) } & $\mathrm{MoS}_{\mathrm{x}} \mathrm{O}_{\mathrm{y}}$ & Nanosheets & 120 & 55 & {$[80]$} \\
\hline & $\mathrm{MoS}_{\mathrm{x}} \mathrm{Cl}_{\mathrm{y}}$ & Flakes@graphene & 160 & 46 & [115] \\
\hline & $\mathrm{MoS}_{\mathrm{x}} \mathrm{Se}_{\mathrm{y}}$ & Nanoflakes & 164 & 48 & [66] \\
\hline & $\mathrm{MoSe}_{\mathrm{x}} \mathrm{Te}_{\mathrm{y}}$ & Thin films & 410 & 62 & [120] \\
\hline & $\mathrm{N}$-doped $\mathrm{WS}_{2}$ & Nanosheets & 127 & 70 & [123] \\
\hline & P-doped $\mathrm{MoS}_{2}$ & Nanosheets & 43 & 34 & [124] \\
\hline \multirow{9}{*}{ Ternary (double cation) } & MoWS $_{x}$ & Thin film & 315 & 46 & [126] \\
\hline & MoWS & Coating@carbon cloth & 198 & 54 & [127] \\
\hline & $\mathrm{Mo}_{\mathrm{x}} \mathrm{W}_{1-\mathrm{x}} \mathrm{S}_{2}$ & Nanoflakes@carbon & 137 & 53 & [128] \\
\hline & $\mathrm{Zn}$-doped $\mathrm{MoS}_{2}$ & Roselike nanosheets & 110 & 51 & [129] \\
\hline & Ta-doped $\mathrm{MoS}_{2}$ & \multirow{2}{*}{ Micro particles } & 660 & 265 & \multirow{2}{*}{ [130] } \\
\hline & $\mathrm{Nb}$-doped $\mathrm{MoS}_{2}$ & & 680 & 190 & \\
\hline & MoWCoS & Nanosheets@rGO & 282 & 41 & [134] \\
\hline & $\mathrm{Ag}_{2} \mathrm{WS}_{4}$ & Micro-cubes & 320 & 62 & [135] \\
\hline & $\mathrm{MoS}_{\mathrm{x}} @ \mathrm{NbS}_{2}$ & Nanoflakes & 164 & 43 & [136] \\
\hline \multirow{4}{*}{ Quaternary } & $\mathrm{Cu}_{2} \mathrm{Mo}\left(\mathrm{S}_{\mathrm{y}} \mathrm{Se}_{1-\mathrm{y}}\right)_{4}$ & Nanosheets & 170 & 52 & [64] \\
\hline & $\mathrm{MoSe}_{2} @ \mathrm{Cu}_{2} \mathrm{MoS}_{4}$ & Nanodots@nanosheets & 176 & 75 & [138] \\
\hline & $\mathrm{Cu}_{2} \mathrm{~W}\left(\mathrm{~S}_{\mathrm{y}} \mathrm{Se}_{1-\mathrm{y}}\right)$ & Nanoparticles & 320 & 46 & [137] \\
\hline & MoNiNC & Coating@Ni foam & 110 & 65 & [140] \\
\hline
\end{tabular}

\section{Conclusions}

We have summarized the recent progress in the development of ternary and quaternary TMCs as electrocatalysts for the water splitting especially for HER. To date, different types of TMCs electrodes consisting of various structures and chemical compositions (including nanoparticles, nanosheets, films and composites) have exhibited excellent HER efficiencies. It is revealed that to improve the catalytic activity of TMCs, two main strategies are being pursued: (i) structure engineering of TMCs to expose additional active sites or provide conductive pathways to fully utilize the materials' catalytic potential (extrinsic) and (ii) chemical modification through heteroatom substitution to enhance hydrogen adsorption by decreasing the $\Delta \mathrm{G}_{\mathrm{H}}$ values (intrinsic). However, many challenges remain associated with the use of TMCs as electrocatalysts. The electrocatalytic activities are affected by the morphology, structure and density of active sites, therefore, close attention should be paid to the specific surface area and chemical composition of the designed TMCs electrocatalysts. In this regards, TMCs consisting of small nanoparticles or containing heterostructures with conductive materials have shown great advantages due to their large number of active sites and high conductivity but these kind of materials are easy to aggregate and show poor stability. The strategy to form ternary or quaternary TMCs electrodes may be a feasible way to solve stability problem. In the case of ternary and quaternary with rich active sites, shows great promises for scalable application but further utilization of inactive basal planes remains to be undertaken. As for the hierarchical structures of TMCs on conductive template or self-organized nanostructures can be effective way to further utilizations of active sites for efficient electrocatalytic activity. For this method, the ease of preparation, cost-effectiveness, repeatability and stability are all important factors which would strongly affect the practical applications of all these catalysts. 
In addition, the improvement of the inherent activity of TMCs electrocatalysts is important for efficient electrocatalytic activity for water splitting. Potential strategies to improve inherent activity include elemental substitution in host TMCs materials. Although this heteroatom substitution method has not been realized for active edge sites of TMCs, chalcogen-atom substitution to form chemical strain for activation of basal planes is a good example showing how such an effect could be realized. However, substitution near the active edge sites of TMCs still need further investigation to provide clear insight for the efficient electrocatalytic activity. Further study could be focus on biomimetic and molecular catalysts using discrete molecular units as catalysts for efficient electrocatalytic activity. Stabilization of molecular catalysts with suitable substrates, such as metal organic framework (MOF) and finding bimetallic organometallic complexes with terminal chalcogen ligands could provide another insight for non-noble metal electrocatalysts.

Owing to the demand for renewable energy, the field of the electrochemical water splitting using TMCs as electrocatalyst has been experiencing a renaissance in recent years. Despite encouraging results in research laboratory, few results have demonstrated the use of TMCs electrocatalysts in large-scale applications. Thus, a great deal of effort is still needed for further expanding the search for high-performance electrocatalysts and exploring the practical use of the efficient advanced electrocatalysts.

Funding: This work was supported by the National Research Foundation of Korea (NRF) under grant no. NRF-2017R1D1A1B03032791, National Research Foundation of Korea (NRF) under grant no. NRF-2016M3A7B4900119 and, Nano-Material Technology Development Program through the National Research Foundation of Korea (NRF) funded by the Ministry of Science, ICT and Future Planning grant no. NRF-2017M3A7B4041987.

Conflicts of Interest: The authors declare no conflict of interest.

\section{References}

1. Walter, M.G.; Warren, E.L.; McKone, J.R.; Boettcher, S.W.; Mi, Q.; Santori, E.A.; Lewis, N.S. Solar Water Splitting Cells. Chem. Rev. 2010, 110, 6446-6473. [CrossRef] [PubMed]

2. Balat, M.; Balat, H. Biogas as a Renewable Energy Source-A Review. Energy Sources Part A Recover. Util. Environ. Effects 2009, 31, 1280-1293. [CrossRef]

3. Shi, L.; Zhao, T. Recent advances in inorganic 2D materials and their applications in lithium and sodium batteries. J. Mater. Chem. A 2017, 5, 3735-3758. [CrossRef]

4. Das, S.; Pandey, D.; Thomas, J.; Roy, T. The Role of Graphene and Other 2D Materials in Solar Photovoltaics. Adv. Mater. 2018, 1802722. [CrossRef] [PubMed]

5. Withers, F.; Del Pozo-Zamudio, O.; Mishchenko, A.; Rooney, A.P.; Gholinia, A.; Watanabe, K.; Taniguchi, T.; Haigh, S.J.; Geim, A.K.; Tartakovskii, A.I.; et al. Light-emitting diodes by band-structure engineering in van der Waals heterostructures. Nat. Mater. 2015, 14, 301. [CrossRef] [PubMed]

6. Azam, A.; Kim, J.; Park, J.; Novak, T.G.; Tiwari, A.P.; Song, S.H.; Kim, B.; Jeon, S. Two-Dimensional $\mathrm{WO}_{3}$ Nanosheets Chemically Converted from Layered $\mathrm{WS}_{2}$ for High-Performance Electrochromic Devices. Nano Lett. 2018, 18, 5646-5651. [CrossRef] [PubMed]

7. Novak, T.G.; Shin, H.; Kim, J.; Kim, K.; Azam, A.; Nguyen, C.V.; Park, S.H.; Song, J.Y.; Jeon, S. Low-Cost Black Phosphorus Nanofillers for Improved Thermoelectric Performance in PEDOT:PSS Composite Films. ACS Appl. Mater. Interfaces 2018, 10, 17957-17962. [CrossRef] [PubMed]

8. Dong, Y.; Mallineni, S.S.K.; Maleski, K.; Behlow, H.; Mochalin, V.N.; Rao, A.M.; Gogotsi, Y.; Podila, R. Metallic MXenes: A new family of materials for flexible triboelectric nanogenerators. Nano Energy 2018, 44, $103-110$. [CrossRef]

9. Turner, J.A. Sustainable Hydrogen Production. Science 2004, 305, 972-974. [CrossRef] [PubMed]

10. Dresselhaus, M.S.; Thomas, I.L. Alternative energy technologies. Nature 2001, 414, 332. [CrossRef] [PubMed]

11. Rostrup-Nielsen, J.R. Fuels and Energy for the Future: The Role of Catalysis. Catal. Rev. 2004, 46, $247-270$. [CrossRef]

12. Bockris, J.O.M. The origin of ideas on a Hydrogen Economy and its solution to the decay of the environment. Int. J. Hydrogen Energy 2002, 27, 731-740. [CrossRef] 
13. Lasia, A. Hydrogen evolution reaction. In Handbook of Fuel Cells; John Wiley \& Sons, Ltd.: Hoboken, NJ, USA, 2010. [CrossRef]

14. Phuruangrat, A.; Ham, D.J.; Thongtem, S.; Lee, J.S. Electrochemical hydrogen evolution over $\mathrm{MoO}_{3}$ nanowires produced by microwave-assisted hydrothermal reaction. Electrochem. Commun. 2009, 11, 1740-1743. [CrossRef]

15. Kotrel, S.; Bräuninger, S. Industrial Electrocatalysis. In Handbook of Heterogeneous Catalysis; Wiley-VCH Verlag GmbH \& Co. KGaA: Weinheim, Germany, 2008.

16. Nørskov, J.K.; Bligaard, T.; Logadottir, A.; Kitchin, J.R.; Chen, J.G.; Pandelov, S.; Stimming, U. Trends in the Exchange Current for Hydrogen Evolution. J. Electrochem. Soc. 2005, 152, J23-J26. [CrossRef]

17. Chen, J.; Lim, B.; Lee, E.P.; Xia, Y. Shape-controlled synthesis of platinum nanocrystals for catalytic and electrocatalytic applications. Nano Today 2009, 4, 81-95. [CrossRef]

18. Greeley, J.; Jaramillo, T.F.; Bonde, J.; Chorkendorff, I.; Nørskov, J.K. Computational high-throughput screening of electrocatalytic materials for hydrogen evolution. Nat. Mater. 2006, 5, 909. [CrossRef] [PubMed]

19. Morales-Guio, C.G.; Stern, L.-A.; Hu, X. Nanostructured hydrotreating catalysts for electrochemical hydrogen evolution. Chem. Soc. Rev. 2014, 43, 6555-6569. [CrossRef] [PubMed]

20. Faber, M.S.; Jin, S. Earth-abundant inorganic electrocatalysts and their nanostructures for energy conversion applications. Energy Environ. Sci. 2014, 7, 3519-3542. [CrossRef]

21. Gao, M.-R.; Xu, Y.-F.; Jiang, J.; Yu, S.-H. Nanostructured metal chalcogenides: Synthesis, modification, and applications in energy conversion and storage devices. Chem. Soc. Rev. 2013, 42, 2986-3017. [CrossRef] [PubMed]

22. Chhowalla, M.; Shin, H.S.; Eda, G.; Li, L.-J.; Loh, K.P.; Zhang, H. The chemistry of two-dimensional layered transition metal dichalcogenide nanosheets. Nat. Chem. 2013, 5, 263. [CrossRef] [PubMed]

23. Voiry, D.; Yang, J.; Chhowalla, M. Recent Strategies for Improving the Catalytic Activity of 2D TMD Nanosheets Toward the Hydrogen Evolution Reaction. Adv. Mater. 2016, 28, 6197-6206. [CrossRef] [PubMed]

24. Bard, A.J.; Faulkner, L.R. Electrochemical Methods: Fundamentals and Applications; John Wiley \& Sons: Hoboken, NJ, USA, 2007.

25. Godula-Jopek, A. Hydrogen Production by Electrolysis; Wiley-VCH: Weinheim, Germany, 2015.

26. Bockris, J.O.M.; Potter, E.C. The Mechanism of the Cathodic Hydrogen Evolution Reaction. J. Electrochem. Soc. 1952, 99, 169-186. [CrossRef]

27. Trasatti, S. Work function, electronegativity, and electrochemical behaviour of metals: III. Electrolytic hydrogen evolution in acid solutions. J. Electroanal. Chem. Interfacial Electrochem. 1972, 39, 163-184. [CrossRef]

28. Tributsch, H.; Bennett, J.C. Electrochemistry and photochemistry of $\mathrm{MoS}_{2}$ layer crystals. I. J. Electroanal. Chem. Interfacial Electrochem. 1977, 81, 97-111. [CrossRef]

29. Gileadi, E. Physical Electrochemistry: Fundamentals, Techniques and Applications; John Wiley \& Sons: Hoboken, NJ, USA, 2011.

30. Carmo, M.; Fritz, D.L.; Mergel, J.; Stolten, D. A comprehensive review on PEM water electrolysis. Int. J. Hydrogen Energy 2013, 38, 4901-4934. [CrossRef]

31. Giovanni, C.D.; Reyes-Carmona, Á.; Coursier, A.; Nowak, S.; Grenèche, J.M.; Lecoq, H.; Mouton, L.; Rozière, J.; Jones, D.; Peron, J.; et al. Low-Cost Nanostructured Iron Sulfide Electrocatalysts for PEM Water Electrolysis. ACS Catal. 2016, 6, 2626-2631. [CrossRef]

32. Seh, Z.W.; Kibsgaard, J.; Dickens, C.F.; Chorkendorff, I.; Nørskov, J.K.; Jaramillo, T.F. Combining theory and experiment in electrocatalysis: Insights into materials design. Science 2017, 355, eaad4998. [CrossRef] [PubMed]

33. Zou, X.; Zhang, Y. Noble metal-free hydrogen evolution catalysts for water splitting. Chem. Soc. Rev. 2015, 44, 5148-5180. [CrossRef] [PubMed]

34. Vesborg, P.C.K.; Seger, B.; Chorkendorff, I. Recent Development in Hydrogen Evolution Reaction Catalysts and Their Practical Implementation. J. Phys. Chem. Lett. 2015, 6, 951-957. [CrossRef] [PubMed]

35. Hunt, S.T.; Nimmanwudipong, T.; Román-Leshkov, Y. Engineering Non-sintered, Metal-Terminated Tungsten Carbide Nanoparticles for Catalysis. Angew. Chem. Int. Ed. 2014, 53, 5131-5136. [CrossRef] 
36. Wu, H.B.; Xia, B.Y.; Yu, L.; Yu, X.-Y.; Lou, X.W. Porous molybdenum carbide nano-octahedrons synthesized via confined carburization in metal-organic frameworks for efficient hydrogen production. Nat. Commun. 2015, 6, 6512. [CrossRef] [PubMed]

37. Vrubel, H.; Hu, X. Molybdenum Boride and Carbide Catalyze Hydrogen Evolution in both Acidic and Basic Solutions. Angew. Chem. Int. Ed. 2012, 51, 12703-12706. [CrossRef] [PubMed]

38. Chen, W.F.; Wang, C.H.; Sasaki, K.; Marinkovic, N.; Xu, W.; Muckerman, J.T.; Zhu, Y.; Adzic, R.R. Highly active and durable nanostructured molybdenum carbide electrocatalysts for hydrogen production. Energy Environ. Sci. 2013, 6, 943-951. [CrossRef]

39. Shi, Z.; Nie, K.; Shao, Z.-J.; Gao, B.; Lin, H.; Zhang, H.; Liu, B.; Wang, Y.; Zhang, Y.; Sun, X.; et al. Phosphorus-Mo2C@carbon nanowires toward efficient electrochemical hydrogen evolution: Composition, structural and electronic regulation. Energy Environ. Sci. 2017, 10, 1262-1271. [CrossRef]

40. Popczun, E.J.; McKone, J.R.; Read, C.G.; Biacchi, A.J.; Wiltrout, A.M.; Lewis, N.S.; Schaak, R.E. Nanostructured Nickel Phosphide as an Electrocatalyst for the Hydrogen Evolution Reaction. J. Am. Chem. Soc. 2013, 135, 9267-9270. [CrossRef] [PubMed]

41. Chung, D.Y.; Jun, S.W.; Yoon, G.; Kim, H.; Yoo, J.M.; Lee, K.-S.; Kim, T.; Shin, H.; Sinha, A.K.; Kwon, S.G.; et al. Large-Scale Synthesis of Carbon-Shell-Coated FeP Nanoparticles for Robust Hydrogen Evolution Reaction Electrocatalyst. J. Am. Chem. Soc. 2017, 139, 6669-6674. [CrossRef] [PubMed]

42. Huang, Z.; Chen, Z.; Chen, Z.; Lv, C.; Humphrey, M.G.; Zhang, C. Cobalt phosphide nanorods as an efficient electrocatalyst for the hydrogen evolution reaction. Nano Energy 2014, 9, 373-382. [CrossRef]

43. Shi, Y.; Zhang, B. Recent advances in transition metal phosphide nanomaterials: Synthesis and applications in hydrogen evolution reaction. Chem. Soc. Rev. 2016, 45, 1529-1541. [CrossRef] [PubMed]

44. McEnaney, J.M.; Chance Crompton, J.; Callejas, J.F.; Popczun, E.J.; Read, C.G.; Lewis, N.S.; Schaak, R.E. Electrocatalytic hydrogen evolution using amorphous tungsten phosphide nanoparticles. Chem. Commun. 2014, 50, 11026-11028. [CrossRef] [PubMed]

45. McEnaney, J.M.; Crompton, J.C.; Callejas, J.F.; Popczun, E.J.; Biacchi, A.J.; Lewis, N.S.; Schaak, R.E. Amorphous Molybdenum Phosphide Nanoparticles for Electrocatalytic Hydrogen Evolution. Chem. Mater. 2014, 26, 4826-4831. [CrossRef]

46. Yin, J.; Fan, Q.; Li, Y.; Cheng, F.; Zhou, P.; Xi, P.; Sun, S. Ni-C-N Nanosheets as Catalyst for Hydrogen Evolution Reaction. J. Am. Chem. Soc. 2016, 138, 14546-14549. [CrossRef] [PubMed]

47. Wang, Z.-L.; Hao, X.-F.; Jiang, Z.; Sun, X.-P.; Xu, D.; Wang, J.; Zhong, H.-X.; Meng, F.-L.; Zhang, X.-B. C and N Hybrid Coordination Derived Co-C-N Complex as a Highly Efficient Electrocatalyst for Hydrogen Evolution Reaction. J. Am. Chem. Soc. 2015, 137, 15070-15073. [CrossRef] [PubMed]

48. Zou, X.; Huang, X.; Goswami, A.; Silva, R.; Sathe, B.R.; Mikmeková, E.; Asefa, T. Cobalt-Embedded Nitrogen-Rich Carbon Nanotubes Efficiently Catalyze Hydrogen Evolution Reaction at All pH Values. Angew. Chem. Int. Ed. 2014, 53, 4372-4376. [CrossRef] [PubMed]

49. Chianelli, R.R.; Siadati, M.H.; De la Rosa, M.P.; Berhault, G.; Wilcoxon, J.P.; Bearden, R.; Abrams, B.L. Catalytic Properties of Single Layers of Transition Metal Sulfide Catalytic Materials. Catal. Rev. 2006, 48, 1-41. [CrossRef]

50. Kisielowski, C.; Ramasse, Q.M.; Hansen, L.P.; Brorson, M.; Carlsson, A.; Molenbroek, A.M.; Topsøe, H.; Helveg, S. Imaging $\mathrm{MoS}_{2}$ Nanocatalysts with Single-Atom Sensitivity. Angew. Chem. Int. Ed. 2010, 49, 2708-2710. [CrossRef] [PubMed]

51. Tiwari, A.P.; Yoo, H.; Lee, J.; Kim, D.; Park, J.H.; Lee, H. Prevention of sulfur diffusion using MoS $_{2}$-intercalated 3D-nanostructured graphite for high-performance lithium-ion batteries. Nanoscale 2015, 7, 11928-11933. [CrossRef] [PubMed]

52. Huang, X.; Zeng, Z.; Zhang, H. Metal dichalcogenide nanosheets: Preparation, properties and applications. Chem. Soc. Rev. 2013, 42, 1934-1946. [CrossRef] [PubMed]

53. Bonaccorso, F.; Lombardo, A.; Hasan, T.; Sun, Z.; Colombo, L.; Ferrari, A.C. Production and processing of graphene and 2d crystals. Mater. Today 2012, 15, 564-589. [CrossRef]

54. Kim, J.; Yoon, G.; Kim, J.; Yoon, H.; Baek, J.; Lee, J.H.; Kang, K.; Jeon, S. Extremely large, non-oxidized graphene flakes based on spontaneous solvent insertion into graphite intercalation compounds. Carbon 2018, 139, 309-316. [CrossRef] 
55. Novak, T.G.; Kim, J.; Song, S.H.; Jun, G.H.; Kim, H.; Jeong, M.S.; Jeon, S. Fast P3HT Exciton Dissociation and Absorption Enhancement of Organic Solar Cells by PEG-Functionalized Graphene Quantum Dots. Small 2016, 12, 994-999. [CrossRef] [PubMed]

56. Park, K.H.; Kim, B.H.; Song, S.H.; Kwon, J.; Kong, B.S.; Kang, K.; Jeon, S. Exfoliation of Non-Oxidized Graphene Flakes for Scalable Conductive Film. Nano Lett. 2012, 12, 2871-2876. [CrossRef] [PubMed]

57. Liu, N.; Kim, P.; Kim, J.H.; Ye, J.H.; Kim, S.; Lee, C.J. Large-Area Atomically Thin $\mathrm{MoS}_{2}$ Nanosheets Prepared Using Electrochemical Exfoliation. ACS Nano 2014, 8, 6902-6910. [CrossRef] [PubMed]

58. Eunyoung, L.; Jinwook, B.; Ji Su, P.; Jin, K.; Jong Min, Y.; Seokwoo, J. Effect of nucleation density on the crystallinity of graphene grown from mobile hot-wire-assisted CVD. 2D Mater. 2019, 6, 011001.

59. Lee, J.; Baek, J.; Ryu, G.H.; Lee, M.J.; Oh, S.; Hong, S.K.; Kim, B.-H.; Lee, S.-H.; Cho, B.J.; Lee, Z.; et al. High-Angle Tilt Boundary Graphene Domain Recrystallized from Mobile Hot-Wire-Assisted Chemical Vapor Deposition System. Nano Lett. 2014, 14, 4352-4359. [CrossRef] [PubMed]

60. Baek, J.; Novak, T.G.; Kim, H.; Lee, J.; Jang, B.; Lee, J.; Jeon, S. Analysis of contact resistance in single-walled carbon nanotube channel and graphene electrodes in a thin film transistor. Nano Converg. 2017, 4, 35. [CrossRef] [PubMed]

61. Chang, K.; Chen, W. 1-Cysteine-Assisted Synthesis of Layered $\mathrm{MoS}_{2}$ /Graphene Composites with Excellent Electrochemical Performances for Lithium Ion Batteries. ACS Nano 2011, 5, 4720-4728. [CrossRef] [PubMed]

62. Guan, Z.; Ni, S.; Hu, S. Tunable Electronic and Optical Properties of Monolayer and Multilayer Janus MoSSe as a Photocatalyst for Solar Water Splitting: A First-Principles Study. J. Phys. Chem. C 2018, 122, 6209-6216. [CrossRef]

63. Tan, W.; Wei, Z.; Liu, X.; Liu, J.; Fang, X.; Fang, D.; Wang, X.; Wang, D.; Tang, J.; Fan, X. Ordered and Disordered Phases in Mo1-xWxS2 Monolayer. Sci. Rep. 2017, 7, 15124. [CrossRef] [PubMed]

64. Tiwari, A.P.; Kim, D.; Kim, Y.; Prakash, O.; Lee, H. Highly active and stable layered ternary transition metal chalcogenide for hydrogen evolution reaction. Nano Energy 2016, 28, 366-372. [CrossRef]

65. Lu, A.-Y.; Zhu, H.; Xiao, J.; Chuu, C.-P.; Han, Y.; Chiu, M.-H.; Cheng, C.-C.; Yang, C.-W.; Wei, K.-H.; Yang, Y.; et al. Janus monolayers of transition metal dichalcogenides. Nat. Nanotechnol. 2017, 12, 744. [CrossRef] [PubMed]

66. Gong, Q.; Cheng, L.; Liu, C.; Zhang, M.; Feng, Q.; Ye, H.; Zeng, M.; Xie, L.; Liu, Z.; Li, Y. Ultrathin $\mathrm{MoS}_{2(1-\mathrm{x})} \mathrm{Se}_{2 \mathrm{x}}$ Alloy Nanoflakes For Electrocatalytic Hydrogen Evolution Reaction. ACS Catal. 2015, 5, 2213-2219. [CrossRef]

67. Xu, K.; Wang, F.; Wang, Z.; Zhan, X.; Wang, Q.; Cheng, Z.; Safdar, M.; He, J. Component-Controllable $\mathrm{WS}_{2(1-\mathrm{x})} \mathrm{Se}_{2 \mathrm{x}}$ Nanotubes for Efficient Hydrogen Evolution Reaction. ACS Nano 2014, 8, 8468-8476. [CrossRef] [PubMed]

68. Song, S.H.; Kim, B.H.; Choe, D.-H.; Kim, J.; Kim, D.C.; Lee, D.J.; Kim, J.M.; Chang, K.J.; Jeon, S. Bandgap Widening of Phase Quilted, 2D MoS 2 by Oxidative Intercalation. Adv. Mater. 2015, 27, 3152-3158. [CrossRef] [PubMed]

69. Pruss, E.A.; Snyder, B.S.; Stacy, A.M. A New Layered Ternary Sulfide: Formation of $\mathrm{Cu}_{2} \mathrm{WS}_{4}$ by Reaction of WS and $\mathrm{Cu}^{+}$Ions. Angew. Chem. Int. Ed. Eng. 1993, 32, 256-257. [CrossRef]

70. Hinnemann, B.; Moses, P.G.; Bonde, J.; Jørgensen, K.P.; Nielsen, J.H.; Horch, S.; Chorkendorff, I.; Nørskov, J.K. Biomimetic Hydrogen Evolution: $\mathrm{MoS}_{2}$ Nanoparticles as Catalyst for Hydrogen Evolution. J. Am. Chem. Soc. 2005, 127, 5308-5309. [CrossRef] [PubMed]

71. Tsai, C.; Chan, K.; Abild-Pedersen, F.; Nørskov, J.K. Active edge sites in $\mathrm{MoSe}_{2}$ and WSe $\mathrm{W}_{2}$ catalysts for the hydrogen evolution reaction: A density functional study. Phys. Chem. Chem. Phys. 2014, 16, 13156-13164. [CrossRef] [PubMed]

72. Lassalle-Kaiser, B.; Merki, D.; Vrubel, H.; Gul, S.; Yachandra, V.K.; Hu, X.; Yano, J. Evidence from in Situ X-ray Absorption Spectroscopy for the Involvement of Terminal Disulfide in the Reduction of Protons by an Amorphous Molybdenum Sulfide Electrocatalyst. J. Am. Chem. Soc. 2015, 137, 314-321. [CrossRef] [PubMed]

73. Sun, T.; Wang, J.; Chi, X.; Lin, Y.; Chen, Z.; Ling, X.; Qiu, C.; Xu, Y.; Song, L.; Chen, W.; et al. Engineering the Electronic Structure of $\mathrm{MoS}_{2}$ Nanorods by N and Mn Dopants for Ultra-Efficient Hydrogen Production. ACS Catal. 2018, 8, 7585-7592. [CrossRef]

74. Xiao, W.; Liu, P.; Zhang, J.; Song, W.; Feng, Y.P.; Gao, D.; Ding, J. Dual-Functional N Dopants in Edges and Basal Plane of $\mathrm{MoS}_{2}$ Nanosheets Toward Efficient and Durable Hydrogen Evolution. Adv. Energy Mater. 2016, 7, 1602086. [CrossRef] 
75. Han, X.; Tong, X.; Liu, X.; Chen, A.; Wen, X.; Yang, N.; Guo, X.-Y. Hydrogen Evolution Reaction on Hybrid Catalysts of Vertical $\mathrm{MoS}_{2}$ Nanosheets and Hydrogenated Graphene. ACS Catal. 2018, 8, 1828-1836. [CrossRef]

76. Kumar, P.; Viswanath, B. Horizontally and vertically aligned growth of strained $\mathrm{MoS}_{2}$ layers with dissimilar wetting and catalytic behaviors. CrystEngComm 2017, 19, 5068-5078. [CrossRef]

77. Jaramillo, T.F.; Jørgensen, K.P.; Bonde, J.; Nielsen, J.H.; Horch, S.; Chorkendorff, I. Identification of Active Edge Sites for Electrochemical H2 Evolution from $\mathrm{MoS}_{2}$ Nanocatalysts. Science 2007, 317, 100-102. [CrossRef] [PubMed]

78. Tsai, C.; Chan, K.; Nørskov, J.K.; Abild-Pedersen, F. Theoretical insights into the hydrogen evolution activity of layered transition metal dichalcogenides. Surf. Sci. 2015, 640, 133-140. [CrossRef]

79. Yan, Y.; Xia, B.; Xu, Z.; Wang, X. Recent Development of Molybdenum Sulfides as Advanced Electrocatalysts for Hydrogen Evolution Reaction. ACS Catal. 2014, 4, 1693-1705. [CrossRef]

80. Xie, J.; Zhang, J.; Li, S.; Grote, F.; Zhang, X.; Zhang, H.; Wang, R.; Lei, Y.; Pan, B.; Xie, Y. Controllable Disorder Engineering in Oxygen-Incorporated $\mathrm{MoS}_{2}$ Ultrathin Nanosheets for Efficient Hydrogen Evolution. J. Am. Chem. Soc. 2013, 135, 17881-17888. [CrossRef] [PubMed]

81. Xie, J.; Zhang, H.; Li, S.; Wang, R.; Sun, X.; Zhou, M.; Zhou, J.; Lou, X.W.; Xie, Y. Defect-Rich MoS 2 Ultrathin Nanosheets with Additional Active Edge Sites for Enhanced Electrocatalytic Hydrogen Evolution. Adv. Mater. 2013, 25, 5807-5813. [CrossRef] [PubMed]

82. Laursen, A.B.; Kegnæs, S.; Dahl, S.; Chorkendorff, I. Molybdenum sulfides-Efficient and viable materials for electro-And photoelectrocatalytic hydrogen evolution. Energy Environ. Sci. 2012, 5, 5577-5591. [CrossRef]

83. Yu, Y.; Huang, S.-Y.; Li, Y.; Steinmann, S.N.; Yang, W.; Cao, L. Layer-Dependent Electrocatalysis of MoS for $^{2}$ Hydrogen Evolution. Nano Lett. 2014, 14, 553-558. [CrossRef] [PubMed]

84. Kibsgaard, J.; Chen, Z.; Reinecke, B.N.; Jaramillo, T.F. Engineering the surface structure of $\mathrm{MoS}_{2}$ to preferentially expose active edge sites for electrocatalysis. Nat. Mater. 2012, 11, 963. [CrossRef] [PubMed]

85. Kong, D.; Wang, H.; Cha, J.J.; Pasta, M.; Koski, K.J.; Yao, J.; Cui, Y. Synthesis of $\mathrm{MoS}_{2}$ and MoSe 2 Films with Vertically Aligned Layers. Nano Lett. 2013, 13, 1341-1347. [CrossRef] [PubMed]

86. Tsai, C.; Abild-Pedersen, F.; Nørskov, J.K. Tuning the $\mathrm{MoS}_{2}$ Edge-Site Activity for Hydrogen Evolution via Support Interactions. Nano Lett. 2014, 14, 1381-1387. [CrossRef] [PubMed]

87. Li, Y.; Wang, H.; Xie, L.; Liang, Y.; Hong, G.; Dai, H. MoS 2 Nanoparticles Grown on Graphene: An Advanced Catalyst for the Hydrogen Evolution Reaction. J. Am. Chem. Soc. 2011, 133, 7296-7299. [CrossRef] [PubMed]

88. Yang, J.; Voiry, D.; Ahn, S.J.; Kang, D.; Kim, A.Y.; Chhowalla, M.; Shin, H.S. Two-Dimensional Hybrid Nanosheets of Tungsten Disulfide and Reduced Graphene Oxide as Catalysts for Enhanced Hydrogen Evolution. Angew. Chem. Int. Ed. 2013, 52, 13751-13754. [CrossRef] [PubMed]

89. Nai, J.; Lu, Y.; Yu, L.; Wang, X.; Lou, X.W. Formation of Ni-Fe Mixed Diselenide Nanocages as a Superior Oxygen Evolution Electrocatalyst. Adv. Mater. 2017, 29, 1703870. [CrossRef] [PubMed]

90. Fang, M.; Dong, G.; Wei, R.; Ho, J.C. Hierarchical Nanostructures: Design for Sustainable Water Splitting. Adv. Energy Mater. 2017, 7, 1700559. [CrossRef]

91. Yu, L.; Yu, X.Y.; Lou, X.W. The Design and Synthesis of Hollow Micro-/Nanostructures: Present and Future Trends. Adv. Mater. 2018, 30, 1800939. [CrossRef] [PubMed]

92. Nai, J.; Lou, X.W. Hollow Structures Based on Prussian Blue and Its Analogs for Electrochemical Energy Storage and Conversion. Adv. Mater. 2018, 1706825. [CrossRef] [PubMed]

93. Deng, J.; Li, H.; Wang, S.; Ding, D.; Chen, M.; Liu, C.; Tian, Z.; Novoselov, K.S.; Ma, C.; Deng, D.; et al. Multiscale structural and electronic control of molybdenum disulfide foam for highly efficient hydrogen production. Nat. Commun. 2017, 8, 14430. [CrossRef] [PubMed]

94. Zhang, J.; Liu, S.; Liang, H.; Dong, R.; Feng, X. Hierarchical Transition-Metal Dichalcogenide Nanosheets for Enhanced Electrocatalytic Hydrogen Evolution. Adv. Mater. 2015, 27, 7426-7431. [CrossRef] [PubMed]

95. Sun, L.; Wang, T.; Zhang, L.; Sun, Y.; Xu, K.; Dai, Z.; Ma, F. Mace-like hierarchical $\mathrm{MoS}_{2} / \mathrm{NiCo}_{2} \mathrm{~S}_{4}$ composites supported by carbon fiber paper: An efficient electrocatalyst for the hydrogen evolution reaction. J. Power Sources 2018, 377, 142-150. [CrossRef]

96. Liao, M.; Zeng, G.; Luo, T.; Jin, Z.; Wang, Y.; Kou, X.; Xiao, D. Three-dimensional coral-like cobalt selenide as an advanced electrocatalyst for highly efficient oxygen evolution reaction. Electrochim. Acta 2016, 194, 59-66. [CrossRef] 
97. Yu, X.-Y.; Yu, L.; Wu, H.B.; Lou, X.W. Formation of Nickel Sulfide Nanoframes from Metal-Organic Frameworks with Enhanced Pseudocapacitive and Electrocatalytic Properties. Angew. Chem. Int. Ed. 2015, 54, 5331-5335. [CrossRef] [PubMed]

98. Yu, X.-Y.; Feng, Y.; Jeon, Y.; Guan, B.; Lou, X.W.; Paik, U. Formation of Ni-Co-MoS 2 Nanoboxes with Enhanced Electrocatalytic Activity for Hydrogen Evolution. Adv. Mater. 2016, 28, 9006-9011. [CrossRef] [PubMed]

99. Liu, Y.; Zhang, J.; Li, Y.; Yuan, G.; Niu, X.; Zhang, X.; Wang, Q. Self-Templated Synthesis of Co $1-\mathrm{x}$ S Porous Hexagonal Microplates for Efficient Electrocatalytic Oxygen Evolution. ChemElectroChem 2018, 5, 1167-1172. [CrossRef]

100. Kuang, M.; Wang, Q.; Han, P.; Zheng, G. Cu, Co-Embedded N-Enriched Mesoporous Carbon for Efficient Oxygen Reduction and Hydrogen Evolution Reactions. Adv. Energy Mater. 2017, 7, 1700193. [CrossRef]

101. Ganesan, V.; Lim, S.; Kim, J. Hierarchical Nanoboxes Composed of $\mathrm{Co}_{9} \mathrm{~S}_{8}-\mathrm{MoS}_{2}$ Nanosheets as Efficient Electrocatalysts for the Hydrogen Evolution Reaction. Chem. Asian J. 2018, 13, 413-420. [CrossRef] [PubMed]

102. Yu, L.; Xia, B.Y.; Wang, X.; Lou, X.W. General Formation of M-MoS3 (M = Co, Ni) Hollow Structures with Enhanced Electrocatalytic Activity for Hydrogen Evolution. Adv. Mater. 2015, 28, 92-97. [CrossRef] [PubMed]

103. Luo, Z.-M.; Wang, J.-W.; Tan, J.-B.; Zhang, Z.-M.; Lu, T.-B. Self-Template Synthesis of Co-Se-S-O Hierarchical Nanotubes as Efficient Electrocatalysts for Oxygen Evolution under Alkaline and Neutral Conditions. ACS Appl. Mater. Interfaces 2018, 10, 8231-8237. [CrossRef] [PubMed]

104. Zhou, W.; Lu, J.; Zhou, K.; Yang, L.; Ke, Y.; Tang, Z.; Chen, S. CoSe 2 nanoparticles embedded defective carbon nanotubes derived from MOFs as efficient electrocatalyst for hydrogen evolution reaction. Nano Energy 2016, 28, 143-150. [CrossRef]

105. Sun, J.; Chen, Y.; Ren, Z.; Fu, H.; Xiao, Y.; Wang, J.; Tian, G. Self-Supported NiS Nanoparticle-Coupled $\mathrm{Ni}_{2} \mathrm{P}$ Nanoflake Array Architecture: An Advanced Catalyst for Electrochemical Hydrogen Evolution. ChemElectroChem 2017, 4, 1341-1348. [CrossRef]

106. Zhou, W.; Cao, X.; Zeng, Z.; Shi, W.; Zhu, Y.; Yan, Q.; Liu, H.; Wang, J.; Zhang, H. One-step synthesis of $\mathrm{Ni}_{3} \mathrm{~S}_{2}$ nanorod@Ni $(\mathrm{OH})_{2}$ nanosheet core-shell nanostructures on a three-dimensional graphene network for high-performance supercapacitors. Energy Environ. Sci. 2013, 6, 2216-2221. [CrossRef]

107. Binjie, Z.; Yuanfu, C.; Fei, Q.; Xinqiang, W.; Wanli, Z.; Yanrong, L.; Xuesong, L. 3D-hierarchical MoSe 2 nanoarchitecture as a highly efficient electrocatalyst for hydrogen evolution. 2D Mater. 2017, 4, 025092.

108. Bian, L.; Gao, W.; Sun, J.; Han, M.; Li, F.; Gao, Z.; Shu, L.; Han, N.; Yang, Z.-X.; Song, A.; et al. Phosphorus-Doped $\mathrm{MoS}_{2}$ Nanosheets Supported on Carbon Cloths as Efficient Hydrogen-Generation Electrocatalysts. Chem CatChem 2017, 10, 1571-1577. [CrossRef]

109. Zhang, X.; Li, J.; Yang, Y.; Zhang, S.; Zhu, H.; Zhu, X.; Xing, H.; Zhang, Y.; Huang, B.; Guo, S.; et al. $\mathrm{Co}_{3} \mathrm{O}_{4} / \mathrm{Fe}_{0.33} \mathrm{Co}_{0.66} \mathrm{P}$ Interface Nanowire for Enhancing Water Oxidation Catalysis at High Current Density. Adv. Mater. 2018, 1803551. [CrossRef] [PubMed]

110. Wu, M.; Huang, Y.; Cheng, X.; Geng, X.; Tang, Q.; You, Y.; Yu, Y.; Zhou, R.; Xu, J. Arrays of ZnSe/MoSe 2 Nanotubes with Electronic Modulation as Efficient Electrocatalysts for Hydrogen Evolution Reaction. Adv. Mater. Interfaces 2017, 4, 1700948. [CrossRef]

111. Li, H.; Yu, K.; Tang, Z.; Zhu, Z. Experimental and First-Principles Investigation of MoWS 2 with High Hydrogen Evolution Performance. ACS Appl. Mater. Interfaces 2016, 8, 29442-29451. [CrossRef] [PubMed]

112. Zhou, X.; Jiang, J.; Ding, T.; Zhang, J.; Pan, B.; Zuo, J.; Yang, Q. Fast colloidal synthesis of scalable Mo-rich hierarchical ultrathin $\mathrm{MoSe}_{2-\mathrm{x}}$ nanosheets for high-performance hydrogen evolution. Nanoscale 2014, 6, 11046-11051. [CrossRef] [PubMed]

113. Lai, J.; Niu, W.; Luque, R.; Xu, G. Solvothermal synthesis of metal nanocrystals and their applications. Nano Today 2015, 10, 240-267. [CrossRef]

114. Tao, L.; Duan, X.; Wang, C.; Duan, X.; Wang, S. Plasma-engineered $\mathrm{MoS}_{2}$ thin-film as an efficient electrocatalyst for hydrogen evolution reaction. Chem. Commun. 2015, 51, 7470-7473. [CrossRef] [PubMed]

115. Zhang, X.; Meng, F.; Mao, S.; Ding, Q.; Shearer, M.J.; Faber, M.S.; Chen, J.; Hamers, R.J.; Jin, S. Amorphous MoSxCly electrocatalyst supported by vertical graphene for efficient electrochemical and photoelectrochemical hydrogen generation. Energy Environ. Sci. 2015, 8, 862-868. [CrossRef]

116. Tang, H.; Dou, K.; Kaun, C.-C.; Kuang, Q.; Yang, S. MoSe 2 nanosheets and their graphene hybrids: Synthesis, characterization and hydrogen evolution reaction studies. J. Mater. Chem. A 2014, 2, 360-364. [CrossRef] 
117. Zhou, H.; Yu, F.; Huang, Y.; Sun, J.; Zhu, Z.; Nielsen, R.J.; He, R.; Bao, J.; Goddard Iii, W.A.; Chen, S.; et al. Efficient hydrogen evolution by ternary molybdenum sulfoselenide particles on self-standing porous nickel diselenide foam. Nat. Commun. 2016, 7, 12765. [CrossRef] [PubMed]

118. Li, F.; Wei, W.; Zhao, P.; Huang, B.; Dai, Y. Electronic and Optical Properties of Pristine and Vertical and Lateral Heterostructures of Janus MoSSe and WSSe. J. Phys. Chem. Lett. 2017, 8, 5959-5965. [CrossRef] [PubMed]

119. Konkena, B.; Masa, J.; Xia, W.; Muhler, M.; Schuhmann, W. MoSSe@reduced graphene oxide nanocomposite heterostructures as efficient and stable electrocatalysts for the hydrogen evolution reaction. Nano Energy 2016, 29, 46-53. [CrossRef]

120. Kosmala, T.; Coy Diaz, H.; Komsa, H.-P.; Ma, Y.; Krasheninnikov, A.V.; Batzill, M.; Agnoli, S. Metallic Twin Boundaries Boost the Hydrogen Evolution Reaction on the Basal Plane of Molybdenum Selenotellurides. Adv. Energy Mater. 2018, 8, 1800031. [CrossRef]

121. Putungan, D.B.; Lin, S.-H.; Kuo, J.-L. A first-principles examination of conducting monolayer $1 \mathrm{~T}^{\prime}-\mathrm{MX} 2(\mathrm{M}=$ Mo, $W ; X=S$, Se, Te): Promising catalysts for hydrogen evolution reaction and its enhancement by strain. Phys. Chem. Chem. Phys. 2015, 17, 21702-21708. [CrossRef] [PubMed]

122. Gholamvand, Z.; McAteer, D.; Backes, C.; McEvoy, N.; Harvey, A.; Berner, N.C.; Hanlon, D.; Bradley, C.; Godwin, I.; Rovetta, A.; et al. Comparison of liquid exfoliated transition metal dichalcogenides reveals $\mathrm{MoSe}_{2}$ to be the most effective hydrogen evolution catalyst. Nanoscale 2016, 8, 5737-5749. [CrossRef] [PubMed]

123. Sun, C.; Zhang, J.; Ma, J.; Liu, P.; Gao, D.; Tao, K.; Xue, D. N-doped WS2 nanosheets: A high-performance electrocatalyst for the hydrogen evolution reaction. J. Mater. Chem. A 2016, 4, 11234-11238. [CrossRef]

124. Liu, P.; Zhu, J.; Zhang, J.; Xi, P.; Tao, K.; Gao, D.; Xue, D. P Dopants Triggered New Basal Plane Active Sites and Enlarged Interlayer Spacing in $\mathrm{MoS}_{2}$ Nanosheets toward Electrocatalytic Hydrogen Evolution. ACS Energy Lett. 2017, 2, 745-752. [CrossRef]

125. Er, D.; Ye, H.; Frey, N.C.; Kumar, H.; Lou, J.; Shenoy, V.B. Prediction of Enhanced Catalytic Activity for Hydrogen Evolution Reaction in Janus Transition Metal Dichalcogenides. Nano Lett. 2018, 18, 3943-3949. [CrossRef] [PubMed]

126. Tan, S.M.; Pumera, M. Composition-Graded MoWSx Hybrids with Tailored Catalytic Activity by Bipolar Electrochemistry. ACS Appl. Mater. Interfaces 2017, 9, 41955-41964. [CrossRef] [PubMed]

127. Li, C.; Bo, X.; Li, M.; Guo, L. Facile electrodeposition fabrication of molybdenum-tungsten sulfide on carbon cloth for electrocatalytic hydrogen evolution. Int. J. Hydrogen Energy 2017, 42, 15479-15488. [CrossRef]

128. Gan, X.; Lv, R.; Wang, X.; Zhang, Z.; Fujisawa, K.; Lei, Y.; Huang, Z.-H.; Terrones, M.; Kang, F. Pyrolytic carbon supported alloying metal dichalcogenides as free-standing electrodes for efficient hydrogen evolution. Carbon 2018, 132, 512-519. [CrossRef]

129. Shi, Y.; Zhou, Y.; Yang, D.-R.; Xu, W.-X.; Wang, C.; Wang, F.-B.; Xu, J.-J.; Xia, X.-H.; Chen, H.-Y. Energy Level Engineering of $\mathrm{MoS}_{2}$ by Transition-Metal Doping for Accelerating Hydrogen Evolution Reaction. J. Am. Chem. Soc. 2017, 139, 15479-15485. [CrossRef] [PubMed]

130. Chua, X.J.; Luxa, J.; Eng, A.Y.S.; Tan, S.M.; Sofer, Z.; Pumera, M. Negative Electrocatalytic Effects of p-Doping Niobium and Tantalum on $\mathrm{MoS}_{2}$ and $\mathrm{WS}_{2}$ for the Hydrogen Evolution Reaction and Oxygen Reduction Reaction. ACS Catal. 2016, 6, 5724-5734. [CrossRef]

131. Lukowski, M.A.; Daniel, A.S.; Meng, F.; Forticaux, A.; Li, L.; Jin, S. Enhanced Hydrogen Evolution Catalysis from Chemically Exfoliated Metallic $\mathrm{MoS}_{2}$ Nanosheets. J. Am. Chem. Soc. 2013, 135, 10274-10277. [CrossRef] [PubMed]

132. Ambrosi, A.; Sofer, Z.; Pumera, M. $2 \mathrm{H} \rightarrow 1 \mathrm{~T}$ phase transition and hydrogen evolution activity of $\mathrm{MoS}_{2}$, $\mathrm{MoSe}_{2}, \mathrm{WS}_{2}$ and $\mathrm{WSe}_{2}$ strongly depends on the MX2 composition. Chem. Commun. 2015, 51, 8450-8453. [CrossRef] [PubMed]

133. Tsai, C.; Chan, K.; Nørskov, J.K.; Abild-Pedersen, F. Rational design of $\mathrm{MoS}_{2}$ catalysts: Tuning the structure and activity via transition metal doping. Catal. Sci. Technol. 2015, 5, 246-253. [CrossRef]

134. Askari, M.B.; Beheshti-Marnani, A.; Banizi, Z.T.; Seifi, M.; Ramezan Zadeh, M.H. Synthesis and evaluation of MoWCoS/G and MoWCuS/G as new transition metal dichalcogenide nanocatalysts for electrochemical hydrogen evolution reaction. Chem. Phys. Lett. 2018, 691, 243-249. [CrossRef]

135. Zhan, F.; Wang, Q.; Li, Y.; Bo, X.; Wang, Q.; Gao, F.; Zhao, C. Low-Temperature Synthesis of Cuboid Silver Tetrathiotungstate $\left(\mathrm{Ag}_{2} \mathrm{WS}_{4}\right)$ as Electrocatalyst for Hydrogen Evolution Reaction. Inorg. Chem. 2018, 57, 5791-5800. [CrossRef] [PubMed] 
136. Zhou, X.; Lin, S.-H.; Yang, X.; Li, H.; Hedhili, M.N.; Li, L.-J.; Zhang, W.; Shi, Y. MoS - $_{\text {-coated NbS }} 2$ nanoflakes grown on glass carbon: An advanced electrocatalyst for the hydrogen evolution reaction. Nanoscale 2018, 10, 3444-3450. [CrossRef] [PubMed]

137. Tiwari, A.P.; Azam, A.; Novak, T.G.; Prakash, O.; Jeon, S. Chemical strain formation through anion substitution in $\mathrm{Cu}_{2} \mathrm{WS}_{4}$ for efficient electrocatalysis of water dissociation. J. Mater. Chem. A 2018, 6, 7786-7793. [CrossRef]

138. Kim, Y.; Tiwari, A.P.; Prakash, O.; Lee, H. Activation of Ternary Transition Metal Chalcogenide Basal Planes through Chemical Strain for the Hydrogen Evolution Reaction. ChemPlusChem 2017, 82, 785-791. [CrossRef]

139. Gong, Q.; Sheng, S.; Ye, H.; Han, N.; Cheng, L.; Li, Y. MoxW M $_{1-\mathrm{x}}\left(\mathrm{SySe}_{1-\mathrm{y}}\right)_{2}$ Alloy Nanoflakes for High-Performance Electrocatalytic Hydrogen Evolution. Part. Part. Syst. Charact. 2016, 33, 576-582. [CrossRef]

140. Wang, F.; Sun, Y.; He, Y.; Liu, L.; Xu, J.; Zhao, X.; Yin, G.; Zhang, L.; Li, S.; Mao, Q.; et al. Highly efficient and durable MoNiNC catalyst for hydrogen evolution reaction. Nano Energy 2017, 37, 1-6. [CrossRef]

(C) 2018 by the authors. Licensee MDPI, Basel, Switzerland. This article is an open access article distributed under the terms and conditions of the Creative Commons Attribution (CC BY) license (http:/ / creativecommons.org/licenses/by/4.0/). 